\title{
Materialidades, espacio, pensamiento: arqueología de la cognición visual ${ }^{*}$
}

\author{
Materialities, Space, Mind: archaeology of visual cognition
}

\author{
Rafael Millán-Pascual ${ }^{a}$, Luis M. Martínez ${ }^{\mathrm{b}}$, Diego Alonso-Pablos ${ }^{\mathrm{b}}$, Manuel J. Blanco ${ }^{\mathrm{c}}$ \\ y Felipe Criado-Boado ${ }^{a}$
}

Para Juan Vicent

\begin{abstract}
RESUMEN
En el presente artículo se realiza un estudio perceptual de diferentes estilos de cerámica prehistórica de Galicia (con cronología entre el 6000 y el 2000 BP) mediante la técnica de seguimiento de movimientos oculares. Este análisis permite comprobar la relación de la mente con la materialidad y sugiere la existencia de una estrecha imbricación entre el diseñar, el ver y el hacer a lo largo de la historia. El trabajo examina cómo las materializaciones de las prácticas humanas se correlacionan con la cognición y con el contexto sociocultural. Las interrelaciones de la cultura material y el comportamiento perceptual, apuntan a una clara conexión entre la mente, los objetos y el mundo. El trabajo aplica técnicas medibles y numéricas, que permiten hacer una aproximación arqueométrica a temas cognitivos mediante la combinación de las neurociencias con investigación interpretativa y reflexiva. Esta investigación ofrece nuevas perspectivas sobre la cultura material y contribuye a comprender la interrelación entre la mente y el mundo material, así como la existencia de un vínculo transitivo entre formas de pensar, de mirar y de hacer cosas. De este modo, el texto hace algunos aportes para entender las fuerzas materiales que guían la percepción y el pensamiento.
\end{abstract}

\begin{abstract}
This article presents a perceptual study of different styles of prehistoric Galician ceramics (from 6000 to 2000 BP) using the technique of eye-tracking. This analysis demonstrates the material engagement of mind by showing that the visual world fosters the entanglement of doing, seeing, and designing over the course of history. We examine how materializations of human practices relate to cognition and to socio-cultural contexts. The interrelations between material culture and perceptual reactions indicate a clear connection between the mind, objects and the world. We apply measurable and numeric techniques, providing an archaeometric approach to cognitive topics by combining neurosciences with interpretive and reflective research. This research provides new insights into the material culture, contributes to the understanding of the relationship between mind and the material world, and accounts for the transitive engagement between ways of thinking, seeing and making things. Thus the text contributes to understand the material forces driving perception and thought.
\end{abstract}

Palabras clave: cerámica prehistórica; Neolítico; Campaniforme; Edad del Bronce; Edad del Hierro; Arqueología cog-

* Programa de Investigación en Tecnologías para la conservación y revalorización del Patrimonio Cultural CSD2007-00058, Consolider-Ingenio 2010, Ministerio de Economía y Competitividad (trabajo experimental); proyecto BFU2014-58776-r, Ministerio de Economía y Competitividad cofinanciado por el Fondo Europeo de Desarrollo Regional-ERDF, y Programa Severo Ochoa para Centros de Excelencia en I+D (SEV-2013-0317) del Instituto de Neurociencias del CSIC (trabajo en laboratorio de LMM); RFM contrato predoctoral FPU1506682 del Ministerio de Educación. El orden de autores de firma sigue la convención FLA (first-last-author-emphasis).

a Instituto de Ciencias del Patrimonio (Incipit), Consejo Superior de Investigaciones Científicas (CSIC). Avenida de Vigo s/n. 15705 Santiago de Compostela. España. Correos e.: RMP rafael.millan-pascual@incipit.csic.es https://orcid.org/0000-0002-1841-782X;

FCB felipe.criado-boado@incipit.csic.es https://orcid.org/0000-0003-4235-706X

b Instituto de Neurociencias (IN). Consejo Superior de Investigaciones Científicas (CSIC), Campus de San Juan. Sant Joan d'Alacant. Alicante. España. Correos e.: LMM 1.martinez@umh.es https://orcid.org/0000-0002-4803-7545; DAP https://orcid.org/0000-0002-6142-2907

c Dpto. de Psicología organizacional y metodología de las ciencias del comportamiento, Facultad de Psicología. Universidad de Santiago de Compostela (USC). C/ Xosé María Suárez Núñez s/n. Campus Vida. 15782 Santiago de Compostela. España. Correo e.: m.blanco@usc.es https://orcid.org/0000-0001-7372-8148

Recibido 20-IX-2019; aceptado 24-XII-2020.

Copyright: (C) 2021 CSIC. Este es un artículo de acceso abierto distribuido bajo los términos de la licencia de uso y distribución "Creative Commons Reconocimiento 4.0 Internacional" (CC BY 4.0) 
nitiva; cognición visual; racionalidad; materialidad; Arqueología del paisaje.

Key words: Prehistoric pottery; Neolithic; Bell Beaker; Bronze Age; Iron Age; Cognitive Archaeology; visual cognition; mind; materiality; Landscape Archaeology.

\section{TEMAS}

Dos ideas se han popularizado en el debate arqueológico de los últimos años. Una es la capacidad de acción de los objetos. La otra tiene que ver con lo que podríamos llamar una irrupción de la res extensa en los análisis sociales y culturales. La arqueología ha asistido intensamente al reconocimiento de la importancia del cuerpo, el espacio y la materialidad en la acción social. De hecho, la corporeización de las ideas permitió salir del exceso interpretativo al que se había llegado con el posprocesualismo y renovó un interés genuino por las cosas. Cuando se repara algo más, estas ideas han estado ahí desde hace tiempo, bien explícitas en algunas elaboraciones filosóficas o implícitas en diferentes teorías arqueológicas. Recientemente, los llamados "nuevos materialismos" han tratado de integrar ambas cuestiones desplazándolas al terreno de la ontología; la capacidad de acción o la afección de la materialidad en el sujeto se atribuyen al 'ser' de las cosas (Olsen 2011; Olsen et al. 2012; Witmore 2014). Sin embargo, hasta el momento esta solución no ofrece evidencias contrastables que superen el carácter especulativo de sus planteamientos. Ciertamente, la materialidad produce efectos que guardan relación con procesos socio-culturales más amplios, pero destacar esta correlación no basta, como tampoco basta oscurecer la cuestión con ideas más oscuras todavía. En este trabajo adoptamos una perspectiva diferente para abordar el problema de reunir la acción de las cosas y los procesos de corporeización desde los avances aportados por las neurociencias y los estudios de cognición visual de la materialidad. Pensamos que este enfoque abre una puerta para la investigación de la dimensión cognitiva de esos procesos y de paso ilumina aspectos esenciales de aquellas ideas. Además, ofrecemos un método empírico capaz de mediar entre problemas que, desde este punto de vista, no se habían podido pensar conjuntamente: la percepción visual, la cognición y la materialidad.

La corporeización o embodiment (en este trabajo mantendremos el concepto inglés) ha sido planteada en forma de hipótesis: el cuerpo y sus facultades perceptivas realizan buena parte de los procesos cognitivos hasta incluso "reemplazar la necesidad de representaciones mentales complejas" (Wilson y Golonka 2013: 1). Otras formulaciones de este fenómeno han sostenido conjeturas parecidas que además se han demostrado en diferentes ámbitos (Lakoff y Johnson 1980; Malafouris 2013). Estos trabajos apuntan a que el procesamiento cognitivo no ocurre solo a instancias del cerebro, sino en relación con la estructura material de los estímulos perceptivos (Meteyard et al. 2012). Esto supone que el antiguo dualismo entre mente y mundo no remite a dos entidades ontológicas distintas sobre las que a posteriori tuviéramos que decidir cuál de ellas reduce a la otra. Por el contrario, dicha separación es una distinción estrictamente metodológica aplicada a una realidad integrada, en la que mente y mundo avanzan juntos y se retroalimentan mutuamente (Clark y Chalmers 1998; Clark 2011) ${ }^{1}$. La cognición ocurre dentro y fuera de la mente. Existe un embodiment biológico mediante el cual el cerebro reacciona a las ondas electromagnéticas del mundo, como documentan ciertos procesos sinestésicos (Moos et al. 2013) o algunos experimentos bien conocidos como Takete-Maluma (Köhler 1929) o de fonosimbolismo (Hinton et al. 1994; Tsur 2006). Además, también existe un embodiment de más alto nivel que sería el resultado evolutivo de un íntimo entramado entre mente y mundo que ha sido demostrado y es demostrable en muchos campos (Clark y Chalmers 1998; Smail $2008)^{2}$. Investigaciones cognitivas clásicas (Bergson), además de distintas tradiciones filosóficas (MerleauPonty 1945; Guattari 1990; Sohn-Rethel 2017), han planteado esta interrelación desde hace tiempo, pero el impulso de nuevas aproximaciones capaces de elaborar teóricamente los desarrollos más recientes de la neurociencia ha despejado definitivamente la posibilidad de estudiar este dominio en consonancia con los intereses de las ciencias humanas y sociales (Solms y Turnbull 2002; Malabou 2007, 2012; Metzinger 2009; Brassier 2011; Malabou y Johnston 2013). Por su parte, en las ciencias cognitivas se han sucedido las teorías del cerebro social (Dunbar 2009), la mente extendida (Clark y Chalmers 1998; Clark 2011), la mente enactiva (Gallagher y Zahavi 2013) o incluso distribuida (Hutchins 1995; Dunbar et al. 2010). Al mismo tiempo, es cada vez más firme la idea de que la cultura material, no solo los instrumentos concretos sino todo el sistema de objetos que los humanos producen, sería un dispositivo

\footnotetext{
${ }^{1}$ Los perniciosos efectos de un dualismo basado en el reconocimiento de dos entidades íntegras y plenamente independientes son de sobra conocidos, pero esta crítica acertada no debe llevarnos a rechazar las posibilidades de una distinción metodológica (en este caso entre mente y mundo) que nada tiene que ver con lo anterior. Como señala el filósofo Ray Brassier (2011: 7): A dualism is a distinction that fails to explain the connection between the term it distinguishes. Philosophy discriminates, it distinguishes and separates, but always with a view to ultimate integration. In this regard, philosophy discriminates precisely in order to avoid dualism. The animus towards dualism should not excuse insensitivity towards distinction.

2 En Jablonka y Lamb 2005, una visión de la evolución que va más allá de la perspectiva genética.
} 
activo en la configuración de un estrecho vínculo con el mundo (Alberti et al. 2011), con la razón (Malafouris 2010), y entre ambos, lo que se ha concretado en la teoría del material engagement of mind (Malafouris 2013). Nosotros volvemos sobre todo ello con datos e hipótesis sólidas gracias a la aplicación de una nueva metodología que hemos presentado recientemente (Criado-Boado et al. 2019).

Simultáneamente los trabajos que muestran que la tecnología es un factor importante para modelar la mente humana, y que 'la capacidad de acción de los objetos' tiene efectos específicos (Heidegger 1994b; Haraway 1995; Dobres y Robb 2000; Latour 2005; Lemonnier 2012; Lange-Berndt 2015; Robinson y Pallasmaa 2015; Stiegler et al. 2015), refuerzan la impresión de que los procesos cognitivos dependen en gran medida de la materialidad (Ingold 2007). En consecuencia, existe un entramado de humanos, cosas y mundo (como por ejemplo postula el entanglement de Hodder 2012) que interrelacionan la cultura, la biología y la materia. Sin embargo, a día de hoy, los procesos que explicarían esta interrelación apenas se entienden. Los estudios desde las neurociencias y la ciencia cognitiva, aunque avanzan en este sentido, han prestado poca atención a la materialidad y ninguna a secuencias cronológicas con escalas inferiores a la totalidad de la evolución humana. Además, como hemos apuntado más arriba para el caso de los nuevos materialismos, los trabajos realizados desde la arqueología cognitiva y las humanidades tienen fundamentalmente un sesgo especulativo y no dan pie a metodologías de estudio que permitan validar hipótesis con claridad. Por ello sigue siendo muy cierto, como avanzaron Renfrew, Frith y Malafouris (2008), que ahondar en la relación mente-mundo requiere encontrar un tracer o proxy que permita documentar cómo las cosas configuran la razón. Si consiguiéramos encontrar este tracer, se podría resolver la sapient paradox con la que Colin Renfrew se refería al hecho inequívoco, pero sorprendente, de que los aspectos conductuales más noveles del género sapiens hayan aparecido con claridad en una época relativamente tardía (hace 30.000 o 40.000 años), mientras que la base biológica de las especies humanas quedó establecida hace más de 200.000 años ${ }^{3}$.

\footnotetext{
${ }^{3}$ Renfrew ha vuelto en repetidas ocasiones desde 1996 a este argumento. El enunciado más completo de la paradoja sapiens que recogemos a continuación está tomado de Renfrew, Frith y Malafouris (2008: 19351936): If the biological basis of our species has been established perhaps for as much as 200,000 years, then why have the novel behavioural aspects of our "sapient" status taken so long to emerge? One interesting observation that Archaeology allows us to make, and which also poses a great challenge to the neuroscientist, is that many of the crucial and enduring aspects of the human condition (symbols, values, religion, literacy, etc.) appear relatively recently in the archaeological record and can certainly be seen as the emergent products of various cultural devel-
}

A partir de las implicaciones que se derivan de Criado-Boado et al. 2019, en este texto proponemos $\mathrm{y}$, dentro de los términos estrictos de una investigación científica, demostramos que un buen traceador es la 'conducta visual' que, a través de gestos oculares, relaciona la mirada con la cognición visual, siendo por lo tanto un buen proxy que permite aproximarse a esta temática con hipótesis robustas y datos rigurosos. Además, si analizamos la respuesta visual ante objetos de sociedades y periodos muy distintos, podemos acercarnos al tema de manera transversal, examinando qué huella cognitiva producen los objetos de diferentes contextos y momentos históricos y analizando si esta cambia a través del tiempo y el espacio.

Uno de los autores de este trabajo publicó en esta misma revista el artículo "Megalitos, espacio, pensamiento" (Criado-Boado 1989), que apuntaba hacia un modelo interpretativo de la arquitectura monumental y sus orígenes, distinto a los que se habían utilizado hasta la fecha. Ese modelo ponía el énfasis en el megalitismo como forma concreta de materialización del concepto de espacio y en la emergencia de esta estrategia de materialización como expresión de un proceso de transformación del pensamiento que, en concreto, operaba el tránsito del "pensamiento salvaje" de Lévi-Strauss a una racionalidad que inaugura la "domesticación del mundo". Esto abrió una rama de la arqueología del paisaje que en realidad contribuía a una arqueología del pensamiento y del concepto de espacio. Desde entonces, diferentes trabajos han permitido comprobar cómo la concepción del espacio-tiempo propia de cada formación cultural, dio lugar a diferentes formas de arquitectura, paisaje e, incluso, cultural material (Criado-Boado y Villoch 1998; Prieto-Martínez et al. 2003; Gianotti et al. 2011; Troncoso et al. 2011; Santos-Estévez 2012; Criado-Boado 2014; Espinosa-Espinosa y González-García 2017; González-García et al. 2019; Troncoso 2019; Troncoso et al. 2019). Sin embargo, ninguno de ellos demostró por qué ocurre eso. Este texto, muchos años después y desde una perspectiva diferente, profundiza en esa línea de investigación y apunta a una nueva respuesta para resolver cómo se produce la relación del pensamiento con el mundo y el espacio a través de las materialidades. De hecho, su tema no es

\footnotetext{
opmental trajectories, rather than innate biological capacities. Could it be then that brain anatomy and the biological endowment of our species Homo sapiens as this emerged between 200,000 and 100,000 years ago is only part of the story? Moreover, would it be more productive, especially from a long-term perspective, to explore the assumption that human intelligence "spreads out" across the body-world boundary, thus extending beyond skin and skull into culture and the material world?. Somos conscientes de las últimas investigaciones que apuntan a un esquema más complejo sobre el desarrollo de las capacidades simbólicas del Homo sapiens, pero creemos que estos nuevos hallazgos no invalidan la premisa general del problema presentado por Renfrew.
} 
solo la visibilidad, las formas de mirar, la percepción visual y ni siquiera la cognición visual. Lo que unifica todas las temáticas que hemos apuntado aquí, es 'la relación cognitiva entre sistema social y materialidad'.

\section{ALCANCE}

Este estudio desarrolla una investigación que hemos anticipado recientemente (Criado-Boado et al. 2019) y en la que hemos sometido a 'análisis de eyetracking' varias piezas de cerámica prehistórica pertenecientes a diversos estilos cerámicos. En este caso nos centraremos en las implicaciones teóricas, interpretativas y arqueológicas de esos resultados. Creemos conveniente hacerlo así porque el carácter generalista de la revista en la que apareció el primer artículo, orientada a un público científico de amplio espectro y no versado esencialmente en arqueología, no solo puede hacer relativamente oscuro el texto al público arqueológico (sobre todo si además no dispone de conocimientos básicos sobre los mecanismos de la cognición visual), sino que además no permitió extenderse en las consecuencias de esta investigación y sus implicaciones teóricas para la arqueología.

Dado que Criado-Boado et al. 2019 detalla la metodología y los datos empíricos de nuestra investigación de partida, podríamos evitarlos enteramente, pero creemos preferible abordar la siguiente discusión, que es en sí muy teórica, a partir de su presentación sumaria.

En ese artículo intentábamos examinar 'dos hipótesis diferentes'. La primera es que 'la configuración material de la pieza (i.e., del estilo material que representa) impone una forma de mirar que produce reacciones perceptuales más allá de lo que uno esperaría', pues condiciona no solo qué lugares visitamos al explorarla visualmente sino también cómo lo hacemos de una forma homogénea con independencia de los observadores individuales. Esto implica que la representación de la pieza no es algo estático para la mente del observador, sino un modelo dinámico que condiciona su patrón de percepción visual. Dicho de otro modo, esto presupone que el sistema perceptual incluye también a la pieza de forma activa y, por lo tanto, muestra que la percepción es indisociable de la materialidad y su configuración. Desde un punto de vista teórico y filosófico, esta hipótesis ataca un problema no banal que ha ocupado una parte importante de las teorías de la conciencia y la representación: supone plantear una superación del debate histórico sobre la representación que la ha entendido bien como forma material o bien como imagen mental. Las consecuencias de este trabajo apuntan a una superación de esta dualidad. Para que se siga mejor nuestro argumento podemos adelantar lo que veremos más abajo y decir que la estructura de la pieza impone una forma de mirar que no solo marca los lugares que nuestra mirada visita con más frecuencia (que es lo que principalmente se estudia en los análisis de la mirada y de eye-tracking, y lo que predicen la mayor parte de las metodologías de imagen artificial más actuales), sino que predetermina cómo lo hacemos, cómo miramos la pieza, en qué orden y con qué secuencia de gestos visuales.

La segunda hipótesis va un poco más allá de la anterior pues propone, siguiendo algunas conjeturas arqueológicas que hemos planteado en otros trabajos (Prieto Martínez et al. 2003; Bradley 2012; CriadoBoado 2014), que a través del tiempo se operó una 'transición gradual desde el predominio de una mirada horizontal a una mirada vertical'. La transición se correlacionaría con otras características del tipo de sociedad a la que pertenece cada estilo material y, particularmente, con la complejidad social. Esta hipótesis, a su vez, apunta a un problema de investigación más amplio, pues sugiere que la respuesta visual es análoga a la articulación espacial de cada estilo material, y que ambas a su vez siguen un patrón de cambio a través del tiempo y de tipos distintos de sociedades, que está adaptado a, o imbricado con, la evolución social. Es decir, la versión extendida de la segunda hipótesis es que 'formas de mirar, de hacer (estilo) y de vivir (sociedad), están relacionadas' inextricablemente entre sí.

Para entender bien las implicaciones de estas hipótesis y la posibilidad de estudiarlas mediante técnicas de eye-tracking, es necesario tener algunas 'nociones básicas de percepción visual'. Nuestros ojos hacen continuas fijaciones y sacadas mediante movimientos súbitos para desplazar la vista de un punto a otro. Hacemos una media de 4 sacadas por segundo, pero no somos conscientes de ello por el fenómeno que se denomina "continuidad perceptual": nuestros ojos se mueven sin parar, pero nosotros no vemos que nuestra vista se mueva ni tiemble ante el mundo. Tendemos a pensar que miramos lo que queremos cuando en realidad la vista está haciendo múltiples movimientos. Estos son en gran medida no intencionales, como mostramos en este estudio. Fijamos la atención en un objetivo, que es lo que se nos representa nítidamente en nuestras imágenes, pero la vista está haciendo otras cosas. Mediante los movimientos sacádicos constantes, nuestra inteligencia visual hace dos cosas importantes: selecciona los puntos en los que debemos fijarnos a continuación, y construye un modelo estadístico del mundo en nuestra mente. Por eso precisamente los movimientos pupilares son tan informativos: nos permiten acceder a un comportamiento visual que no es intencional, pero es muy revelador de lo que hace la parte visual de nuestro cerebro y por ende de la relación de este con el mundo mediada por la vista. Los movimientos pupilares se pueden registrar con un equipo espe-

Trab. Prehist., 78, N. ${ }^{\circ}$ 1, enero-junio 2021, pp. 7-25, ISSN: 0082-5638

https://doi.org/10.3989/tp.2021.12262 
cial denominado eye-tracker (Fig. 1). En nuestro caso utilizamos un Eyelink II (SR Research Ltd., Osgoode, Ontario, Canada) que registra independientemente los movimientos de cada ojo con una frecuencia de $500 \mathrm{~Hz}$ mediante dos pequeñas cámaras de video. En este tipo de experimento, el sujeto se posiciona delante de una pantalla en la que se le presentan las imágenes que se quiere estudiar (Fig. 2).

Para testar nuestras hipótesis diseñamos un 'proceso experimental' en el que estudiamos 15 cacharros (Fig. 3) característicos de cuatro estilos materiales que pertenecen a cinco momentos crono-culturales distintivos de la misma zona geográfica (distribución en Criado-Boado et al. 2019: fig. ED7), que abarcan un abanico cronológico de 4000 años, y presentan grados distintos y crecientes de complejidad y jerarquización social. Elegimos cerámicas procedentes de la Prehistoria de Galicia (NO de la península ibérica), pero que corresponden a estilos materiales más amplios y que, en líneas generales, comparten rasgos formales con la evolución cerámica del occidente europeo (Gibson 2002). Incluyen ejemplares de cerámica simbólica del Neolítico Final-Calcolítico (Estilo 2 de este estudio), cerámica campaniforme (Estilo 3), y otros estilos que presentan claras concomitancias con cerámicas presentes en otros territorios. El Estilo 1 presenta nítidas semejanzas con las cerámicas del Neolítico Medio del occidente europeo, y los Estilos 4 y 5 son en realidad variantes cronológicas del estilo cerámico perteneciente a la Edad del Hierro.

El diseño del proceso experimental de esta investigación incluyó siete experimentos distintos y sucesivos. En el trabajo Criado-Boado et al. 2019 y en el actual, nos centramos en los resultados empíricos de los tres más significativos. En total estos involucraron a 131 sujetos mayores de edad y en paridad de género. En el experimento 1 (Exp1, código laboratorio EXP 14061) mostramos fotografías de cinco cacharros (Fig. 4), expresamente replicados (Criado-Boado et al. 2019: Supplementary Information SI 1 y SI 2), a partir de un proceso tecnológico que permitió obte-

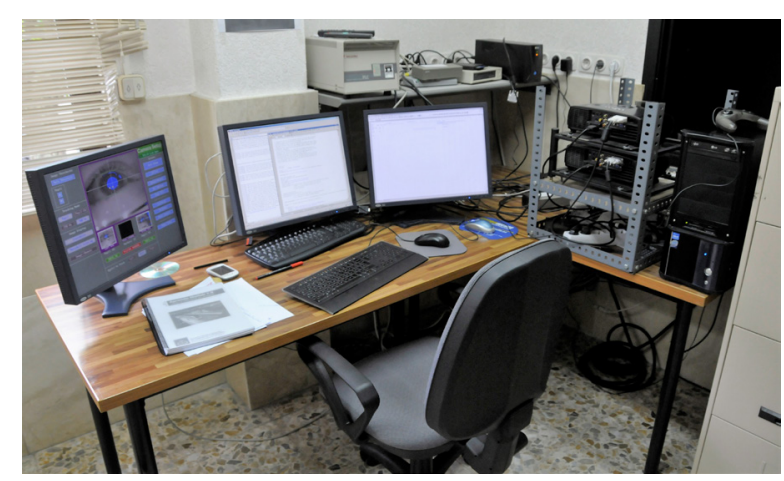

Fig. 1. Fotografía del equipo de técnica de seguimiento de movimientos oculares o eye-tracking utilizado. En color en la edición electrónica.

ner piezas con las mismas características formales y visuales que las originales. La población implicada en este experimento conformaba cuatro grupos muestrales diferenciados. Tres corresponden a diferentes tipos de "expertos": el grupo 1 (G1) estuvo formado por 13 personas familiarizadas con los materiales y que conocían a priori la metodología, las hipótesis de trabajo y los principales objetivos del experimento. Era previsible por lo tanto que su comportamiento visual estuviese predeterminado en el sentido de confirmar las previsiones o de intentar evitarlo para no mostrar sesgo alguno o sentirse condicionado; el G2 incluyó 12 profesionales de la arqueología gallega que conocen y están familiarizados con este tipo de material pero que no disponían de ninguna información previa sobre el experimento, como tampoco los dos siguientes grupos; el G3 agrupó a 11 ceramistas, personas que trabajan cerámica bien como artesanos o artistas. En este caso se suponía que su profesión y familiaridad con la manufactura del material afectarían a su conducta visual. El G4 integró a 25 personas del público general, que eran por lo tanto no-expertos y que tenían niveles de formación muy distintos y procedían de ambientes tanto urbanos como rurales.

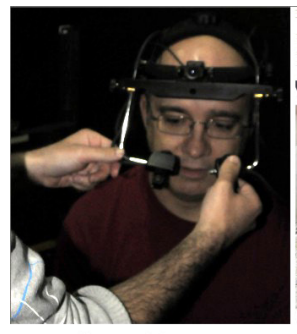

Ajuste del casco

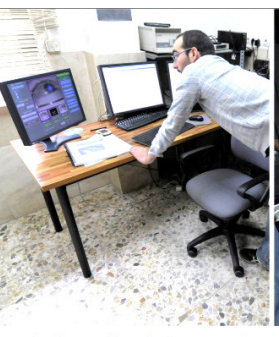

Calibración de la señal

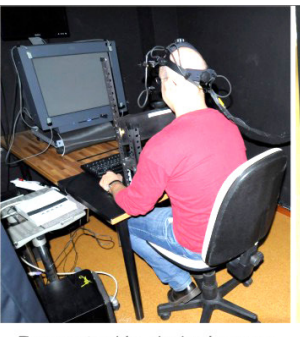

Presentación de imágenes

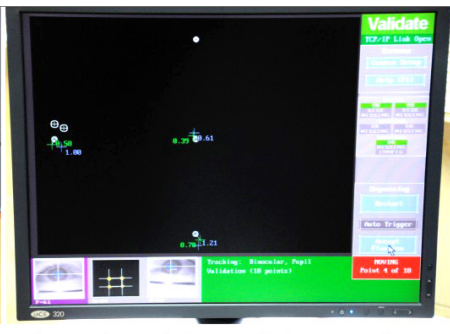

Seguimiento de los movimientos oculares

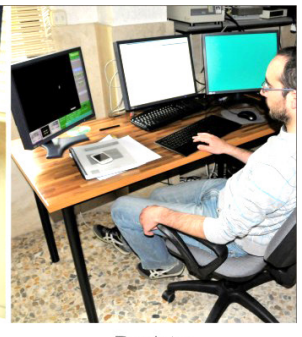

Registro

Fig. 2. Proceso de análisis mostrando a un participante (David Barreiro) y al operador del eye-tracking (Diego Alonso) durante el curso de uno de los experimentos. En color en la edición electrónica. 


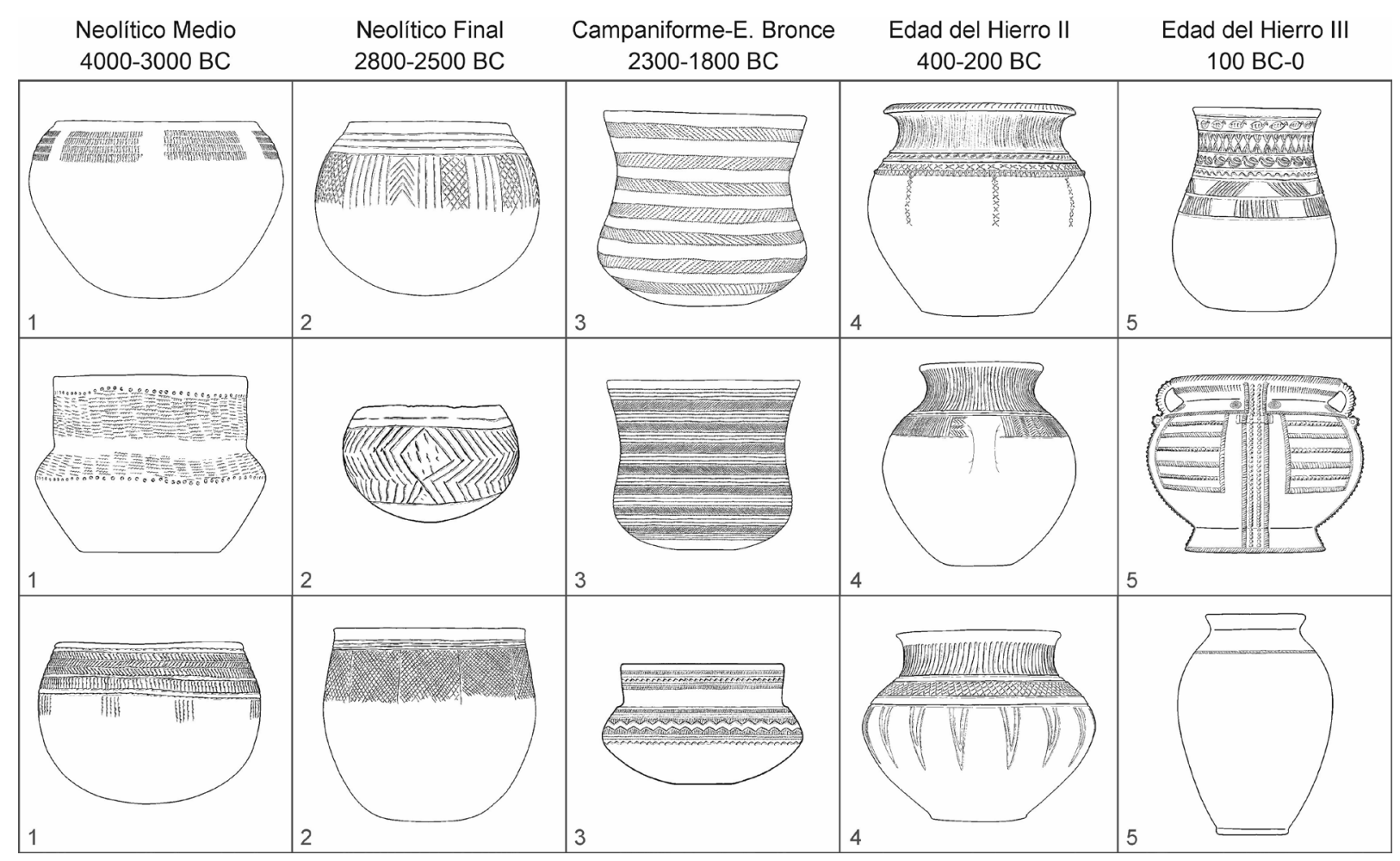

Fig. 3. Cerámicas sometidas a análisis indicando su marco cronológico y estilístico (según Criado Boado et al. 2019: Supplementary Figures, fig. ED1 traducida).
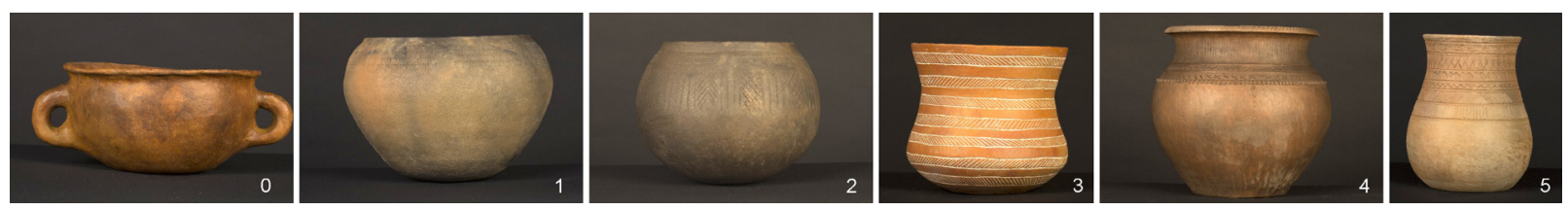

Fig. 4. Fotografías analizadas en el experimento 1 (EXP_14061) (Criado-Boado et al. 2019: Supplementary Figures fig. ED8). En color en la edición electrónica.

El experimento 2 (Exp2, código laboratorio EXP_14091) se hizo sobre 40 dibujos que incluían 15 cerámicas originales (Fig. 3, cinco de ellas de la Fig. 4), al lado de 5 grupos de variación distintos de estas piezas (Fig. 5). Con ello se pretendía falsar los sesgos visuales, forzar artificialmente reacciones visuales provocando sorpresa y, de este modo, someter a control los resultados iniciales. Intervinieron 36 sujetos, 25 de los cuales habían participado en Exp1. Finalmente, el experimento 3 (Exp3, código laboratorio EXP_15011) se basó en 54 fotografías y dibujos de tipo distinto, entre las cuales se introdujeron las piezas de Exp1 junto a variaciones de estas y de otras imágenes que permitirían precisar las hipótesis de trabajo (Fig. 6). Exp2 y Exp3 se hicieron después del análisis preliminar de los resultados de Exp1 y se diseñaron específicamente para testar o falsar sus consecuencias. Así, por ejemplo, si habíamos visto que un estilo decorativo suele mirarse de forma horizontal, en Exp2 dimos la vuelta a la decoración o al cacharro para ver si la respuesta visual se alteraba de forma congruente.

\section{RESULTADOS}

Para analizar los resultados empíricos definimos dos parámetros que nos permitieran procesar la respuesta visual de los experimentos: el $A R$ y el $V i$. El Aspect Ratio $(A R)$ o relación de aspecto establece la proporción horizontal-vertical de cada pieza. El Verti- 


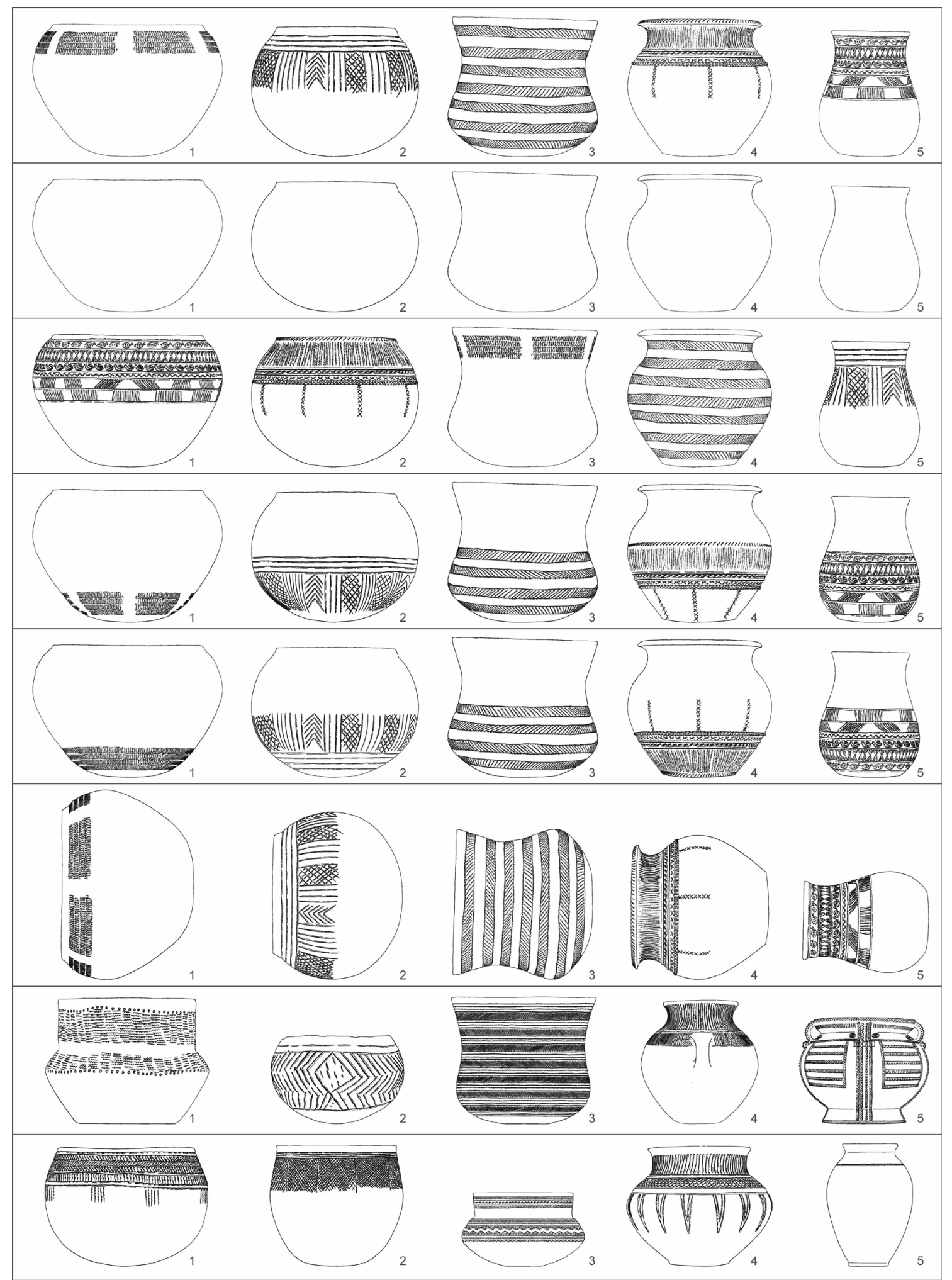

Fig. 5. Dibujos analizados en el experimento 2 (EXP_14091). 


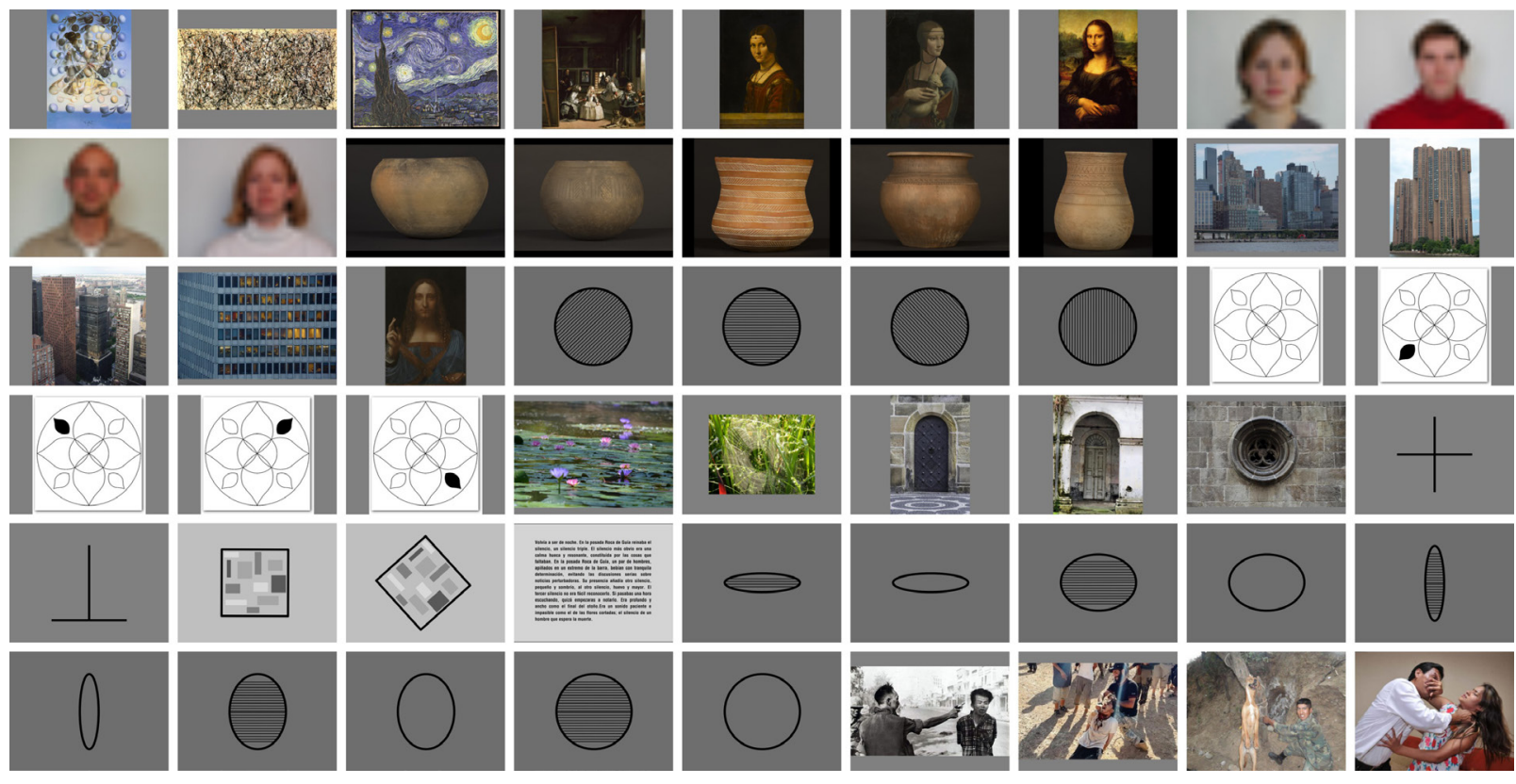

Fig. 6. Elenco de imágenes analizadas en el experimento 3 (EXP_15011) (Criado-Boado et al. 2019: Supplementary Figures fig. ED8). De izquierda a derecha y de arriba abajo: 1. Galatea de las Esferas, Salvador Dalí (1952); 2. Number 31, Jackson Pollock (1950); 3. La noche estrellada, Vincent van Gogh (1889); 4. Las Meninas, Diego Velázquez (1656); 5. La belle ferronière, Leonardo da Vinci (1490-95); 6. La Dama del armiño, Leonardo da Vinci (1490); 7. La Gioconda; 8 a 11: Bustos de diferentes tipos de personas; 12 a 16: Cerámicas 1 a 5 de la figura 4; 17-20: Arquitecturas con diferentes puntos de vista y elementos decorativos y estructurales: 17-21; Salvator Mundi, Leonardo da Vinci (1500); 22 a 30: figuras geométricas; 31 y 32: naturalezas; 33 a 35: elementos arquitectónicos históricos; 36 a 50: variaciones de formas geométricas, y un texto para leer; 52 a 54: fotografías de violencia social, incluyendo terrorismo islamista, y violencia contra animales y mujeres. Todas las figuras son de bases de datos públicas, excepto aquellas bien conocidas que se han sustituido por una referencia. En color en la edición electrónica.

cal index $(V i)$ o índice de verticalidad refleja la relación entre las sacadas de dirección predominantemente horizontal y vertical.

La figura 7 presenta los resultados más importantes recogidos en Criado-Boado et al. 2019. En ella se ve que, mientras el $A R$ de las cerámicas sigue una línea ascendente, la decoración impone una respuesta ocular en la que prima en unos casos la horizontalidad y en otros la verticalidad según refleja el Vi. Esta figura registra además el valor de la saliencia (different visual features that contribute to attentive selection of a stimulus -color, orientation, movement etc., Niubur 2007: 2675) de cada cerámica, y muestra cómo la carga de información visual de cada estilo cerámico funciona como predictor del comportamiento visual.

La figura 8 resume de forma gráfica la preferencia por la exploración horizontal o vertical propia de cada cacharro; incluye un gráfico en el que se representa el porcentaje de sacadas de diferente dirección y se recoge una secuencia de fotografías que muestra, para el total de los sujetos, el lugar y sentido predominante de su mirada a lo largo de intervalos fijos de tiempo. Esta información completa la información sobre el $\mathrm{Vi}$ de la figura 7 mostrándonos la interrelación entre los ángulos de las sacadas y la disposición topológica de la densidad de fijaciones. Aquí queda claro que no solo la carga visual se centra en las franjas decoradas de

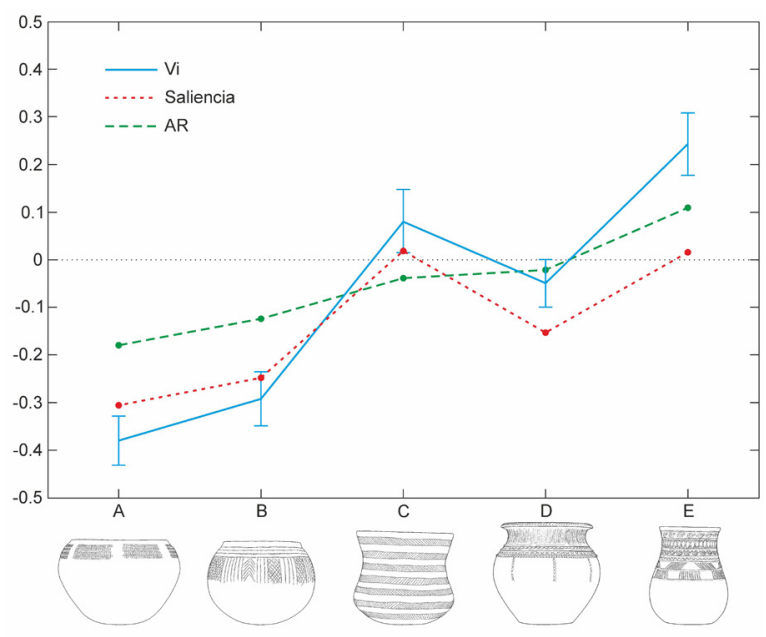

Fig. 7. Valores del Vi (Vertical index o índice de verticalidad), $A R$ (Aspect Ratio o relación de aspecto) y saliencia para los cinco cacharros tipo del experimento 2. A Neolítico Medio 4000-3000BC; B Neolítico Final 2800-2500 BC; C Campaniforme-Edad del Bronce 2300-1800 BC; D Edad del Hierro II 400-200 BC; E Edad del Hierro III 100BC-0. En color en la edición electrónica. 


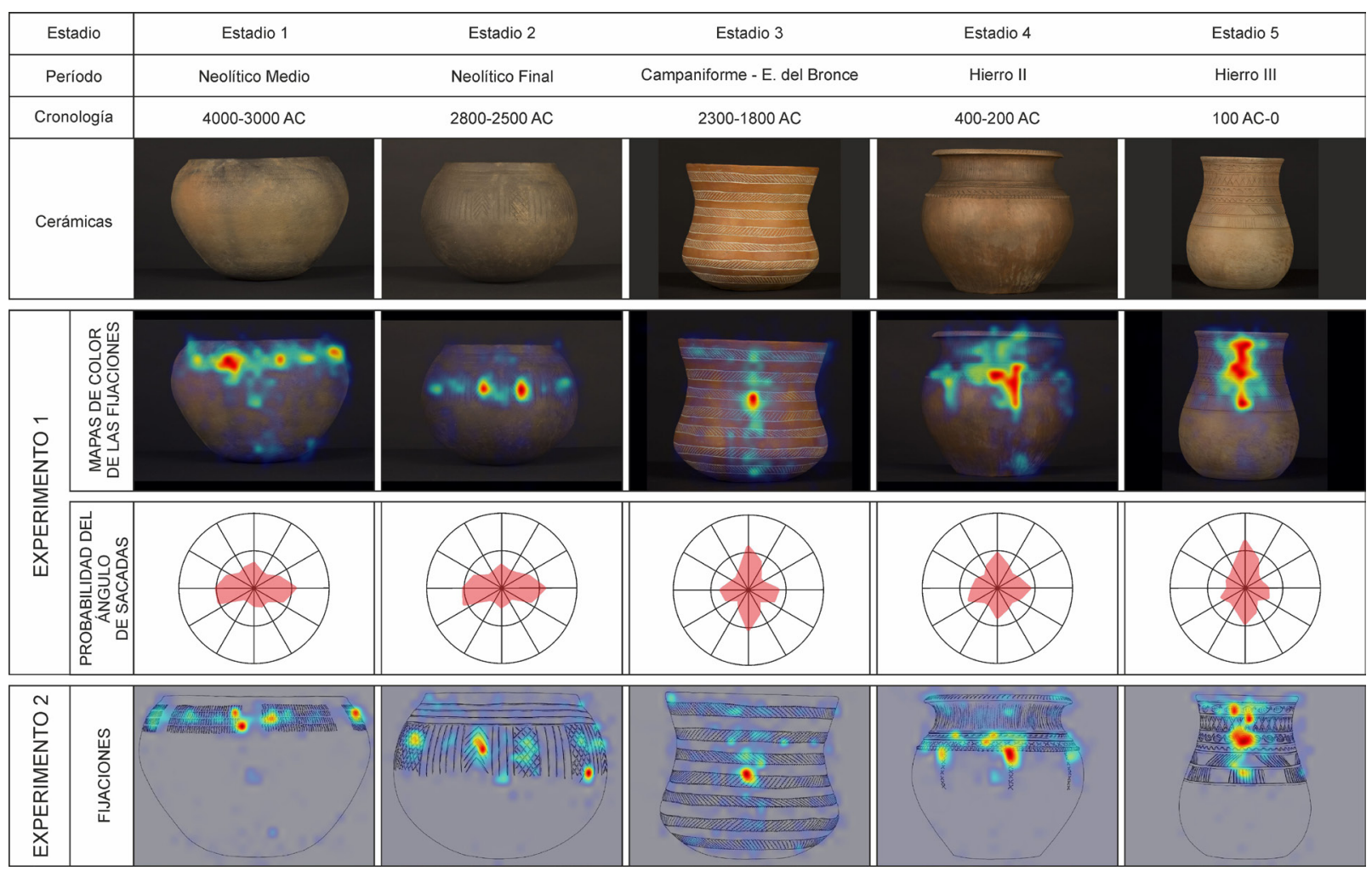

Fig. 8. Comportamiento visual inducido por cada cerámica según los datos de los experimentos 1 y 2. En color en la edición electrónica.

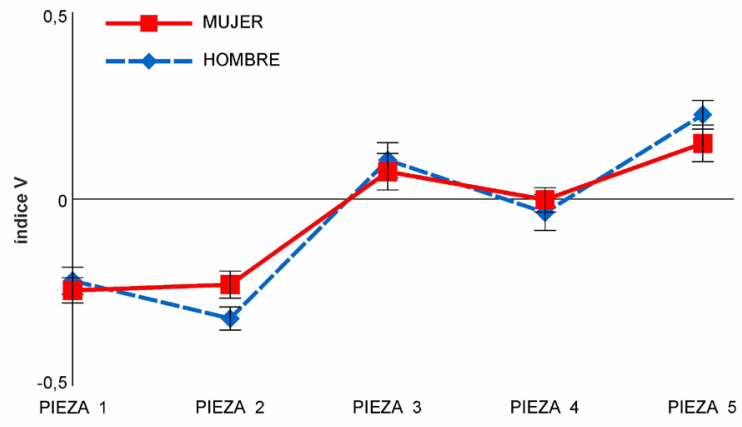

Fig. 9. El Vi según diferencias de género. Vi Vertical index o índice de verticalidad (Criado-Boado et al. 2019: Supplementary information, fig. ED11). En color en la edición electrónica.

cada cacharro, sino que, atendiendo a la configuración y articulación interna del patrón decorativo, el comportamiento visual es distinto.

Los datos muestran que no existen diferencias apreciables entre mujeres y hombres (Fig. 9) ni entre grupos de edad y que el comportamiento de los diferentes grupos muestrales es el mismo (Criado et al. 2019:
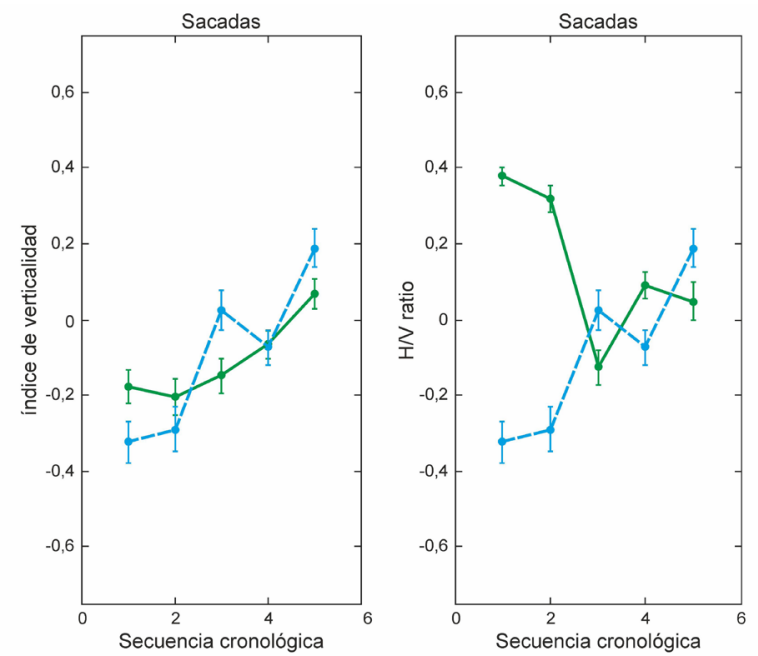

Fig. 10. $V i$ de las cerámicas de la columna 3 de la fig. 6 (línea a trazos) comparado con, a la izquierda, el $V i$ de las mismas piezas sin decoración (línea recta, columna 4, fig. 6) y con, a la derecha, el $V i$ de las piezas en posición acostaba (línea recta, columna 8, fig. 6). Vi Vertical index o índice de verticalidad. En color en la edición electrónica. 


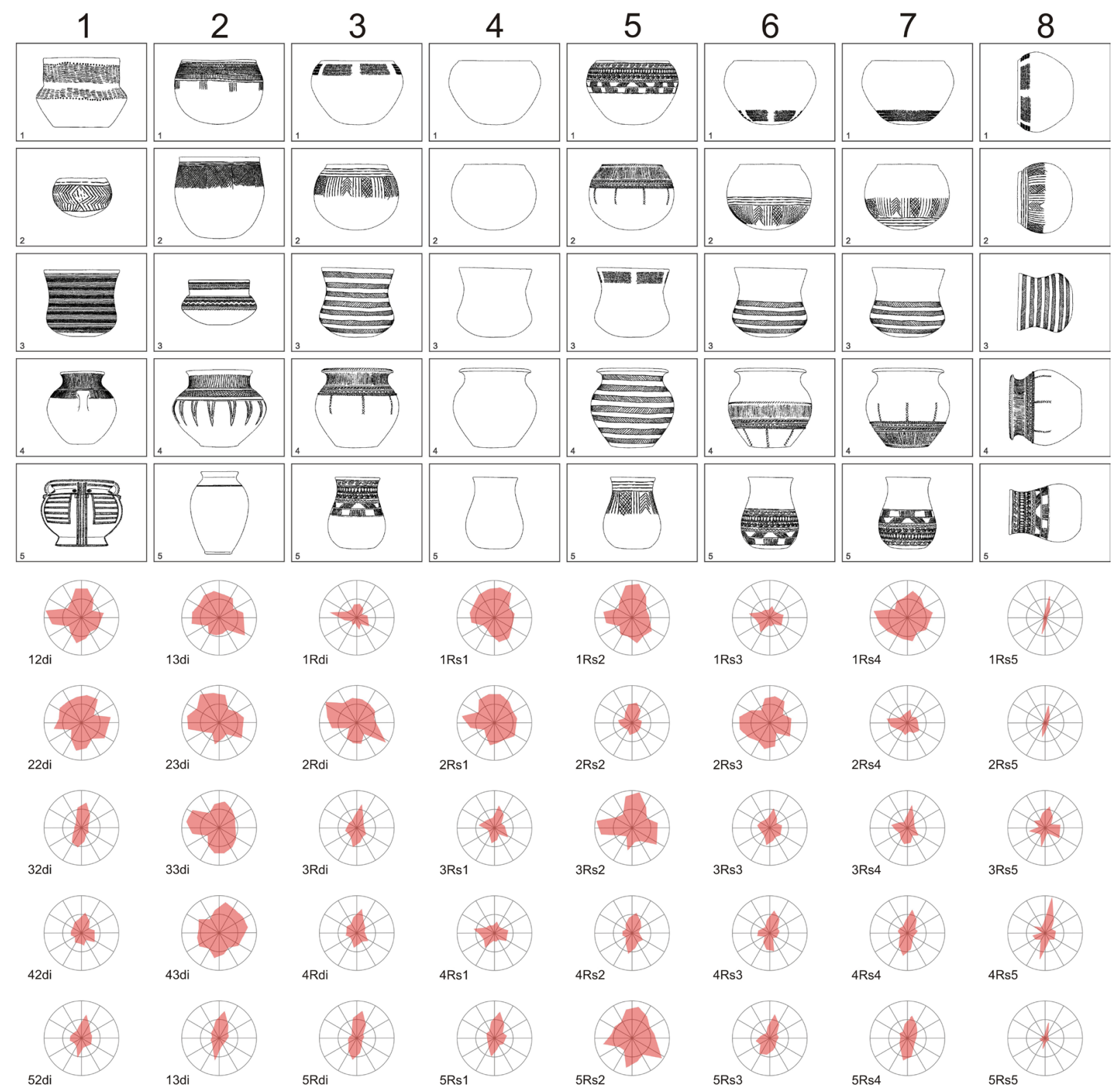

Fig. 11. Dirección de las sacadas en las imágenes del experimento 2. Las columnas 1, 2 y 3 son piezas originales; las restantes son variaciones a partir de las piezas de la columna 3. Estos cambios artificiales permiten ver cómo el comportamiento visual está influido por la decoración específica de cada estilo cerámico. Por ejemplo, al introducir la decoración metopada del Neolítico Final en una jarra del Hierro 3 (imagen 5.5), se horizontaliza la respuesta visual; inversamente, cuando una decoración campaniforme se incluye en una vasija del Hierro 2 , se refuerza una respuesta visual vertical. Esto es muy claro en las imágenes de la columna 8. Al tumbar los cacharros, la respuesta visual sigue el patrón de la decoración (la parte superior en Criado-Boado et al. 2019: supplementary figures, fig. ED9). En color en la edición electrónica.

fig. ED13). Esto en principio podría sorprender, pues en un primer momento se esperaba que la mayor familiaridad con las piezas de arqueólogos y ceramistas, y la mayor indiferencia ante ellas del público general, generaría algún tipo de sesgo o diferencia clara. Pero no emergieron ni siquiera en el G1, el de las personas que tenían un grado mayor de conocimiento sobre los experimentos.

Para el avance de nuestra metodología fue interesante confirmar que el comportamiento visual ante fotografías y dibujos era el mismo (Criado et al. 2019: fig. ED15), por lo que en los Exp2 y 3 trabajamos solo 
con dibujos. Tampoco aparecieron diferencias cuando solo se analizaban cerámicas (Exp1 y Exp2), o cuando se contemplaban (Exp3) entre un aluvión de imágenes variadas (caras, objetos, formas geométricas...) que se miran de formas totalmente distintas a la cerámica.

Análisis más detallados mostraron que el $V i$ registra mucha información sobre la manera de mirar la pieza, un resultado (al igual que otros que derivan de estos experimentos) cuya aplicación e interés trasciende el ámbito disciplinar de la arqueología. Un análisis discriminante linear del Vi permitió mostrar su capacidad para predecir qué pieza se está observando, algo que resalta la fuerza o sobredeterminación que la pieza ejerce en la percepción (Criado et al. 2019: fig. 2B). Es decir, la decoración predetermina la orientación visual de una manera tan decisiva, que a partir de los movimientos visuales se puede identificar la pieza observada. Esta fue una importante consecuencia empírica del trabajo porque ejemplifica de manera significativa la agencia del objeto en el proceso cognitivo.

Realmente el $A R$ y la decoración de cada pieza contribuyen a orientar la exploración visual de un modo sinérgico pero cada uno lo hace de una forma distinta y con un mecanismo diferente. La figura 10 refleja esto al mostrar las variaciones a las que sometimos la serie de piezas originales en Exp2 y Exp3 y al compararla con otras formas artificiales. En condiciones neutras (es decir, sin decoración) el $A R$ y el $V i$ se acoplan bastante bien (Criado et al. 2019: figs. 3a y ED17). Lo mismo se puede decir al analizar el $A R$ y la respuesta visual de la misma forma geométrica con diferentes proporciones H/V (Criado et al. 2019: fig. 3b). En este caso el alargamiento horizontal o vertical de la forma reduce o amplía el $V i$, lo que claramente indica la indeterminación entre el $V i$ y el $A R$. Lo significativo es que, a pesar de ello, el efecto de la decoración modifica el potente impacto de la forma general (medido a través de su $A R$ ) en la orientación de la exploración visual, un efecto que confirma la figura 11 que, a partir de datos de Exp2, ejemplifica cómo el intercambio de formas y decoraciones entre cacharros hace que el $V i$ se modifique sustancialmente.

Exp1 y Exp2 confirmaron que la primera sacada tiende a ser a la izquierda y hacia arriba. Cuando la decoración está en el centro del cacharro o abajo, la mirada se dirige a ella, pero el periodo de latencia es mayor. Este sesgo plantea interesantes relaciones sobre la posibilidad de que la primera sacada esté condicionada por los hábitos de lectura. Pero en el marco de la agencia material que estamos analizando en este trabajo es relevante ver cómo, a pesar de que pueda haber un comportamiento visual preprogramado por los hábitos de lectura, la configuración de la materialidad impone el ritmo del patrón de observación. Exp3 mostró que, al introducir las cerámicas entre otras formas muy dis-

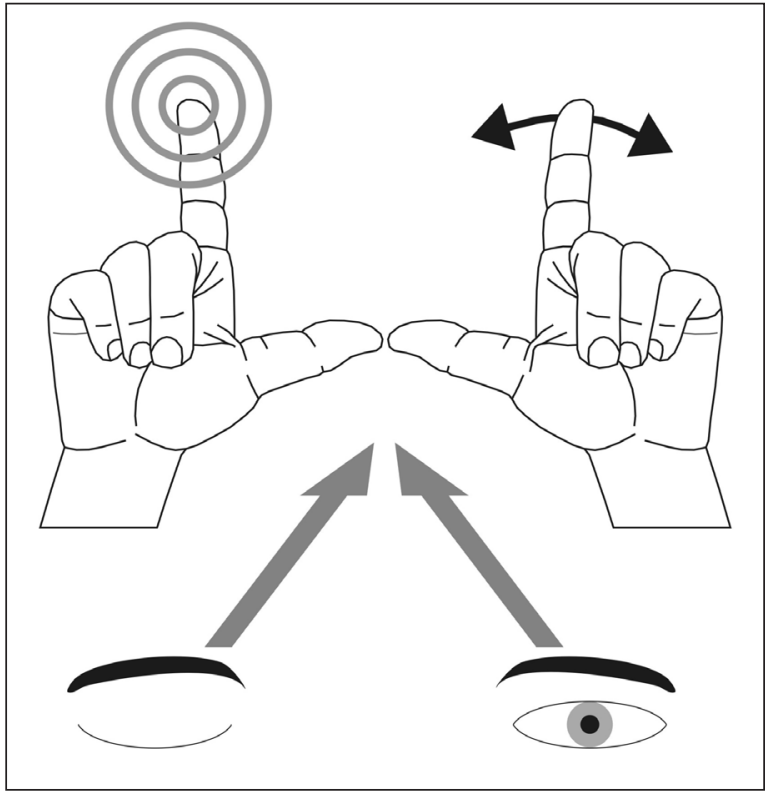

Fig. 12. Experimento del punto ciego.

tintas, se pierde este sesgo de la primera sacada y generalmente al inicio el observador mantiene la vista en el centro. Esto muestra que, según la tarea, el observador cambia su atención y su disposición para mirar. En un experimento solo con cerámicas, el observador adopta una actitud visual análoga a la de la lectura, como si se dispusiese inicialmente a "leer" la decoración. Sin embargo, la fuerza material de la decoración termina alterando y haciendo irrelevante este sesgo. En un experimento como Exp3 con muchas imágenes y de tipo muy distinto, el observador adopta una actitud más neutra, fijando a priori la mirada en el centro a la espera de lo que se vaya a encontrar en la figura que se le muestra. Pero, nuevamente, lo relevante es que pese a ello el análisis del $V i$ de las imágenes cerámicas presentadas en Exp3 muestra un comportamiento igual al documentado en Exp1 y Exp2.

\section{INTERPRETACIONES}

Estos resultados tienen implicaciones que van más allá de las consecuencias tratadas en el trabajo original. Por un lado, dan lugar a interpretaciones arqueológicas y sociales sobre materialidad y cognición que completan las hipótesis de partida (enumeradas en la sección Alcance). Por otro, abren nuevas perspectivas sobre los 'temas' que esbozamos en la primera sección de este texto.

Desde el punto de vista arqueológico y prehistórico, estos resultados confirman que 'la estructura mate- 
rial de la cerámica', más allá de su información visual intrínseca, 'determina la manera como se mira'. Es un importante hallazgo metodológico confirmar que, a través del Vi que compara el porcentaje de sacadas verticales y horizontales, podemos caracterizar la forma de mirar, esto es, el comportamiento visual que cada tipo de estilo cerámico genera. Estos datos avalan la importancia e influencia de la decoración en el proceso visual, algo que resulta particularmente nítido cuando, para hacer el estudio, intercambiamos formas y decoraciones para desambiguar el efecto relativo de cada una de ellas. De alguna forma se puede decir que el $V i$ sigue en primera instancia el $A R$ de los cacharros, pero se diferencia de este último con el añadido de la decoración. Dicho de otro modo, siempre se podría pensar que la forma de un vaso campaniforme es la que conduce la mirada verticalmente. Pero si añadimos la decoración campaniforme en un cacharro tipo cazuela que tiene una decoración que conduce la mirada horizontalmente (Estilo 1), el sentido de observación preferente de este cacharro cambia. Y si le ponemos esa decoración al vaso campaniforme, este pasa a ser contemplado de forma más horizontal.

La decoración conduce el Vi y hace de este una expresión certera del patrón de la mirada adaptado a cada objeto. Hace, además, que el $V i$ se incremente a través del tiempo y lo hace, en nuestra serie analítica, mediante la sustitución de modelos formales horizontales (Estilos 1 y 2) por modelos verticales (Estilo 3) y de estos por modelos jerarquizados verticalmente (Estilo 4 y sobre todo Estilo 5). Los resultados por lo tanto confirman las hipótesis de partida y muestran que cada pieza, es decir, cada estilo cerámico, contiene una información que condiciona por igual la forma de mirar de observadores muy distintos y a todos ellos del mismo modo, como muestra el hecho de que no se aprecien diferencias de género, grupo u otro tipo de sesgos como la lectura. De aquí se sigue que 'el observador individual no produce patrones de mirada particulares', pues su carga subjetiva es menos importante para reconocer y para orientar el modo en el que explora la pieza que la carga que introduce la materialidad de las mismas. En otras palabras, el patrón de exploración es el mismo independientemente del sesgo individual del observador.

Desde un elenco empírico totalmente distinto, estas consecuencias confirmarían los estudios sobre identidad e individualidad que Almudena Hernando (2012, p. ej.) viene planteando desde hace años, toda vez que la materialidad muestra patrones grupales sobre los que además repercute activamente. En el experimento que presentamos abordamos esta cuestión cuando comprobamos que la respuesta visual es análoga al patrón formal de cada estilo material. En efecto, detectamos un cambio simétrico en las formas materiales y las formas de mirarlas a lo largo del tiempo, que además está relacionado con el tipo de relación social de los grupos del pasado, sea esta más igualitaria o jerárquica. En este sentido, si tenemos en cuenta el contexto arqueológico de las piezas de nuestro estudio, un registro que va del Neolítico Medio a la Edad del Hierro Final, comprobamos una tendencia hacia una mayor o menor verticalización de la mirada según el mayor o menor grado de jerarquización social. La 'materialidad produce un efecto agente en la percepción visual' que se impone al observador indistintamente de su posición muestral. Este efecto depende de la articulación interna de la forma material que organiza el campo visual en bandas donde las variaciones significativas se producen bien en el plano horizontal o en el vertical. Por lo tanto, las observaciones de este trabajo nos conducen a un sustrato básico del proceso perceptivo que se mantiene al margen de las diferencias individuales, en parte porque está predeterminado por la propia biología del sistema visual (algo que la neurociencia admite como una constante dados los fuertes constreñimientos biológicos y energéticos del procesamiento visual), y en parte porque está sobredeterminado por la materialidad. Esta sería la principal consecuencia de Criado-Boado et al. (2019), pues mientras está bien aceptado en los estudios de cognición visual que los determinantes biológicos son constantes en la especie humana, la mayor innovación de nuestra aproximación es remarcar que lo que los humanos hacemos, el mundo artificial que generamos, también determina la forma en que esa predeterminación biológica se pone en juego. En este artículo podemos ir algo más lejos que en ese trabajo para remarcar que la incidencia de la biología y la materialidad en la percepción visual no debe confundirse con un supuesto determinismo mecanicista del proceso cognitivo.

No pensamos que pueda desprenderse algo parecido de esta investigación, a pesar de que parezca contradictorio señalar las determinaciones de la cognición y negar al mismo tiempo el determinismo como explicación del proceso cognitivo. En realidad, esta contrariedad es una paradoja aparente que como tal solo se sostiene si pensamos dichas determinaciones en un único plano indiferenciado y excesivamente rígido -como si la mente fuera un circuito eléctrico cerrado-. Por el contrario, el desarrollo de las neurociencias y de la inteligencia artificial señala que los automatismos del cerebro, lejos de parecerse a un mecanicismo rutinario, tienen contradicciones inmanentes que prueban su carácter indeterminado (David Bates, cit. Malabou 2017: 143). La historicidad de la materialidad, tan ampliamente estudiada por la arqueología, refuerza de hecho esta indeterminación de la cognición visual a partir de sus variaciones, transformaciones y desapariciones 
a lo largo de la historia y, por extensión, este anclaje de la mente en el mundo y la historia.

Hay una forma sencilla de mostrar la indeterminación del proceso cognitivo. Existe un experimento muy popular de ilusiones visuales con el que se identifica el efecto en la percepción visual del "punto ciego" de la retina o "papila", el área de la retina de la que surge el nervio óptico y en la que por lo tanto no hay conos ni bastones que permitan recoger sensaciones visuales. Cuando colocamos dos dedos en la posición que recoge la figura 12 , cerramos un ojo y con el otro observamos el dedo del lado contrario, al momento percibimos que el dedo que corresponde al ojo cerrado desaparece. Eso ocurre porque en esta posición lo tenemos exactamente alineado con la papila. Si bajamos el dedo, seguimos viendo lo mismo porque hemos dejado de ver el dedo. Pero este experimento nos muestra además algo sorprendente: en cambio vemos lo que está detrás del dedo. Lo que explica que no veamos el dedo y veamos lo que está detrás (y que en realidad no estamos viendo) es que el proceso de cognición visual rellena la imagen esperada haciendo una proyección de las estadísticas dominantes en su entorno (He y Davis 2001). Como el dedo está solo, nuestra mente no lo puede sustituir, pero las formas y colores que están detrás del dedo y que son una extensión de lo que está a su alrededor, las reconstruimos en el proceso cognitivo visual a pesar de no registrar sensaciones visuales de esa parte del campo observado. Esto se confirma cuando en lugar de un dedo ponemos varios (en realidad el experimento se hizo con barras dibujadas) En este caso el procesamiento visual interpola el dedo que no vemos. Propiamente, vemos sin mirar porque el cerebro parte de probabilidades basadas en el contexto visual para reconstruir las imágenes procesadas. El experimento del punto ciego evidencia que lo que llamamos percepción visual no es un resultado exclusivo del sentido de la vista, sino que pone en juego un proceso cognitivo atravesado de mediaciones (entre ellas la materialidad percibida) que condicionan nuestra mirada. Podemos decir que el cerebro reserva un grado de incertidumbre sobre lo que ve indisociable de los automatismos del proceso cognitivo. La filósofa Catherine Malabou (2017: 145) habla de una dialéctica interna entre el automatismo y la resistencia del automatismo consigo mismo. Nosotros podemos decir con ella que la biología no resta ni cierra el paso a la historia, porque, añadimos, las condiciones biológicas de la mirada hacen de ella un proceso cognitivo abierto. Conocer estos límites es de hecho una manera de poner rostro a viejos problemas epistemológicos. Sobre esto podemos ahondar algo más.

'Para ver no llega con percibir sensaciones, sino que hay que procesarlas cognitivamente'. Esto de hecho es consecuencia de un sistema biológico desarrollado para reducir los costes energéticos del procesamiento visual: nuestra retina tiene una resolución equivalente a 105 megapíxeles, pero el nervio óptico transmite al cerebro imágenes comprimidas de un megapíxel. De hecho, si el cerebro tuviese que procesar imágenes del tamaño original, los humanos precisarían un cerebro de las proporciones de un elefante que consumiría dos Tm de azúcar al día. De ahí que para regenerar en la mente imágenes de calidad, haya que descomprimir las imágenes de baja resolución anteriores incrementando su resolución a partir de modelos estadísticos del mundo visual que la parte visual del cerebro ha generado con base en la memoria de la experiencia. L. Martínez et al. (2014), que han estudiado este fenómeno, hacen una analogía entre el procesado cognitivo de imágenes en el cerebro y la forma cómo funciona la descompresión de imágenes en una cámara digital. Esto, dicho de otro modo, quiere decir que podemos ver sin mirar porque tenemos 'memoria' (volvemos sobre este tema en la siguiente sección).

Una forma de aproximar la interacción sinérgica entre mundo y cognición y prever las implicaciones en términos de racionalidad que esto genera, es pensar que el embodiment es un proceso simétrico de la mente en el mundo y de este en la mente que se produce porque 'la percepción depende de las estadísticas del mundo', de la suma de rasgos materiales de este que son de un modo u otro medibles y expresables numéricamente (Field 1987; Ruderman 1994; Sigman et al 2001; Torralba y Oliva 2003). Nuestra investigación corrobora cómo la percepción es la educación de la atención (Ingold 2007) mediante la materialidad. Pero va más allá: la posibilidad de que la forma de la materia y la forma de mirar se relacionen con la complejidad social (más horizontal en sociedades menos complejas, más vertical en sociedades jerarquizadas), introduce una dimensión adicional a este entramado de interacciones entre mundo, percepción y cognición, que estamos tratando y añade una nueva lectura a los procesos de embodiment. La justificación de esta correlación está implícita en el resultado principal que estos experimentos apuntalan. Pues si hay una relación mundomateria-mente, esta incluye un mundo que no es solo natural (no engloba solo la luz, la geomorfología, el terreno, la fisiografía, la vegetación), sino que incorpora las modificaciones humanas: es decir, el mundo según está constituido por dominios físicos y sociales, por relaciones naturales y sociales, y por materialidades que están producidas natural y culturalmente. Las estadísticas que reflejan el mundo visual incluyen el mundo construido, un mundo que no es solo natural sino también hecho y transformado por el ser humano. Estas evidencias remiten a una relación activa y plural entre el vivir, el hacer y el pensar. En este sentido, no debemos confundir este razonamiento sobre la inte- 
rrelación materia-mente-mundo con la correspondencia 'construir-habitar-pensar' resaltada por Heidegger (1994a). Como vemos, esta investigación no se adentra en ninguna metafísica trascendental del ser y sus revelaciones. En este trabajo mostramos en cambio que las formas de mirar son también formas de pensar, formas de racionalidad, que a su vez pueden distinguirse porque el comportamiento visual no es tanto un proceso guiado únicamente por los sentidos o las percepciones, sino un proceso cognitivo, que implica a la mente y por consiguiente la modela y construye sobre el suelo de la historia ${ }^{4}$.

Podríamos entonces suponer que las personas, que fueron las hacedoras y usuarias originales de las cerámicas estudiadas, habrían mirado a los cacharros de una forma muy semejante a los sujetos actuales que se enfrentan a ellas, ya sea sin conocerlas de antemano o estando familiarizados con ellas. Esto se objetará sin duda a las implicaciones de este trabajo dentro de los ámbitos de la arqueología y las humanidades, pues como buenas disciplinas sociales están obligadas ante todo a dar cuenta de la excepción humana y a pensar la realidad social en sí y para sí, no desde posiciones reduccionistas. Pero creemos que 'nuestras consecuencias superan las visiones dicotómicas tradicionales' (i.e. modernas) entre individuo y sociedad, o biología y cultura. Sin menospreciar la carga semántica e individual que las piezas tenían para los agentes que las hicieron y utilizaron, las conclusiones que alcanzamos aquí apuntan a un plano más basal de la percepción, que no descarta otras lecturas antropológicas y sociales de la materialidad, pero permite comprender la interacción de su configuración y agencia con el proceso cognitivo y la función activa que desempeña entre este y el mundo. Por ello, podemos suponer que la respuesta visual de humanos actuales y de los sujetos originarios no habría variado mucho, ya que en definitiva esa respuesta está mediada por una indiscutible biología común y por una materialidad que es la misma.

\footnotetext{
${ }^{4}$ Cabe aclarar que este estudio plantea un límite a la fenomenología tradicional al dirigirse a las constantes biológicas que condicionan la percepción. El yo fenomenológico (el guiado por los sentidos) no correspondería con el proceso de cognición visual de la mirada, por cuanto dicho proceso no es analizable desde una perspectiva que parta de la primera persona como eje central del estudio. El proceso de cognición visual no es perceptible por uno mismo ni reductible a la conducta o a la experiencia del sujeto, de ahí que para analizarlo se requiera de una terciarización del análisis (es decir, de un análisis en tercera persona). Eso es lo que nos permite hacer la técnica de eye-tracking. Ir más allá del yo fenomenológico abre el camino a una comprensión histórica de la percepción, ya que por un lado permite analizar la manera de mirar a los objetos independientemente del sujeto que mira (nos permite estudiar la mirada en el pasado), pero consolida la necesidad de la investigación histórica para dar cuenta de las relaciones y de las condiciones históricas que han determinado esa forma de mirar (nos permite estudiar la formación de la mirada).
}

Dicho de otro modo, una crítica oportuna de esta investigación es remarcar que la forma de ver la cerámica en los sujetos actuales no tiene por qué indicar nada sobre cómo la vieron los sujetos que fueron sus autores y usuarios originales. Nuestra respuesta es que, excluido el sujeto individual de la ecuación, nos queda un proceso con tres actores: biología, materialidad y contexto socio-cultural. Sabido que dos son constantes (la biología, que no ha cambiado, y la materialidad, que es la misma) y sabido que el tercero no solo cambia, sino que en gran medida es incognoscible en su totalidad por nosotros, podemos deducir que el comportamiento visual es el mismo (porque sobre todo depende de los dos primeros) aunque el sentido de lo que se ve haya variado culturalmente ${ }^{5}$. Nuestro trabajo confirma lo primero, pero respecto a lo segundo se precisan futuras investigaciones ${ }^{6}$.

\section{PERSPECTIVAS}

Esta investigación demuestra el interés de hacer estudios neuro-arqueológicos de épocas relativamente recientes, apunta a la existencia de cambios cognitivos importantes en pocos cientos de años o generaciones, $y$ plantea varias cosas más.

En primer lugar, muestra que las formas de mirar cada pieza (el comportamiento visual) son constantes y regulares para todas las piezas de un mismo estilo. Es decir, 'el estilo guía la mirada' (materiality drives visual behaviour). La forma de mirar está determinada por lo que antes hemos hecho, por el proceso de materialización. Esto es, probablemente, la conclusión

\footnotetext{
5 Para resolver esta cuestión desde las limitaciones de una arqueología que no conoce el patrón de racionalidad implicado en la construcción de sentido por parte de sociedades e individuos a los que no podemos acceder por entero, tendríamos que ver si es posible que la fuerza de la materialidad transmita un sentido que se puede interpretar transculturalmente. Esto requeriría hacer una "arqueología de la cosa" que mediante el estudio formal y contextual de las cosas permitiera acceder a la "cosa" misma, al asunto o argumento que está detrás de ella, a su sentido histórico en suma. Este camino no es imposible, pero es otro camino, que requeriría la revisión de las bases epistemológicas de la disciplina y el ajuste de las conclusiones neurobiológicas a las indeterminaciones abiertas de la antropología humana. A día de hoy, el filósofo Markus Gabriel (2016) está trabajando con más o menos éxito en esa línea que la citada Catherine Malabou (2016) está reelaborando desde otra posición, a partir del problema fundamental de la epigénesis.

${ }^{6}$ Con posteridad a la presentación de este artículo, conocimos la aprobación de un proyecto que dos de los firmantes (FCB y LMM) presentamos conjuntamente con Andy Clark y Johannes Müller a la convocatoria Synergy Grant 2020 del ERC (European Research Council). Este proyecto lleva por título Material minds, Exploring the interactions between predictive brains, cultural artefacts, and embodied visual search y explora en parte las cuestiones que abordamos en este texto. Su acrónimo es XSCAPE, por las razones que se indican a continuación. Está dotado con 10 millones de euros y será realizado desde octubre de 2021 hasta 2027.
} 
más clara de este trabajo. Sobre estos resultados fisiológicos y cognitivos (los movimientos oculares) seguramente podemos adquirir la prueba más objetiva hasta ahora de la vieja tesis arqueológica según la cual los cambios en la materialidad son acordes a los cambios de la estructura social. Co-evolución aquí solo quiere decir que los cambios en uno de los factores van al lado de los cambios en el otro.

En segundo lugar, indica que, dado que el mundo exterior no es solo un mundo físico o natural sino un mundo artificial y producido por el trabajo y la acción humana, 'el mundo que determina la conciencia es también el mundo creado por la conciencia'. Es decir, no hay solo un embodiment del mundo físico, sino también del mundo social. De un modo muy concreto, el mundo social está después del proceso cognitivo visual (porque lo construimos los humanos) y antes (porque lo incorporamos en nuestra mente), ya que una vez que el mundo social está constituido, ejerce una sobredeterminación formal sobre el proceso cognitivo. Hay por tanto una pluralidad de mundos (Gabriel 2015), tantos como la diversidad de acciones y procesos humanos que puedan incidir en lo que aquí llamamos el mundo físico y que arqueológicamente recogemos como realidades históricas concretas.

En tercer lugar, este artículo señala que las formas de mirar a cada estilo también son una forma social. Es decir, 'la mirada y el estilo forman parte de las características de la formación socio-cultural'. Esto ocurre, precisamente, porque el estilo es la materialización del sistema de poder (Prieto-Martínez 2009, 2017); esto es, de la forma social.

En cuarto lugar, el hecho de que nuestras representaciones visuales sean el resultado de un proceso cognitivo basado en sensaciones procesadas contra el modelo de estadísticas del mundo que realiza la parte visual de nuestro cerebro, apunta a otra perspectiva: tanto lo que sentimos como nuestra forma de mirar (comportamiento visual) son intrínsecos a nuestros procesos (y modelos) cognitivos. Es decir, 'la conciencia $^{7}$ y el mundo están simétricamente entretejidos'. La conciencia encarna al mundo, y el mundo emula a la conciencia.

Una implicación ulterior de estos resultados y que también merecería consideración, es que colateralmente permite matizar un aspecto de las aproximaciones antropológicas que parten de modelos ontológicos alternativos. En el fondo, estos se basan en una conceptualización distinta del concepto de representación para defender que en determinadas sociedades no hay una separación entre la realidad y la imagen, sino que

7 En otros trabajos uno de los autores habla de 'racionalidad' (Criado Boado 2012). esta mantiene el estatus de una entidad activa (una presencia) en continuidad con el mundo. La crisis de esta forma de representación es un proceso que adquiere peso en Occidente a partir del Barroco, cuando se inicia la objetivación del proceso epistemológico frente al mundo -Michel Foucault (1966) identificó este proceso en Las palabras y las cosas con el paso del Renacimiento a la Época Clásica-. La relación con los ídolos, la imagen concebida no como representación abstracta del ser, sino como una extensión del mismo, es un ejemplo perdurable de esta concepción anterior a la representación moderna. El giro ontológico, al concebir a los objetos como agentes activos o "actantes" en la terminología de Bruno Latour (2005), evoca a estas tradiciones ontológicas alternativas $\mathrm{y}$, en parte, presta un revestimiento teórico ajustado al carácter activo que el avance tecnológico y digital ha intensificado en las cosas. Desde un aspecto más general, estas elaboraciones teóricas y estos procesos son una muestra de los cambios que hoy día enfrenta una modernidad en la que se vuelven a movilizar sus rasgos constitutivos -la representación ontológica de las cosas es uno de ellos-. Por eso, las nuevas concepciones sobre la representación que postulan las teorías más radicales sobre el embodiment en las ciencias cognitivas, comparten este giro de la representación como presencia al mostrar que la representación no es algo puramente abstracto, autónomo en la mente, sino que involucra la información sensorial y motora aportada por la misma realidad material. De un modo u otro, estas ideas forman parte de un mismo aire de época. Este trabajo corrobora esta conceptualización, pues muestra cómo los objetos, en vez de ser cosas inanimadas o representaciones de entes y valores que en arqueología prehistórica no nos es dado conocer habitualmente, son "actantes" que provocan reacciones, actúan sobre el comportamiento, lo predeterminan y orientan el proceso cognitivo de una u otra forma. Sin embargo, nosotros rehuimos unos modelos que, desde nuestro punto de vista, tienden a ser excesivamente automáticos y efectistas en sus explicaciones (véase Reynoso 2015). Asumir una noción de representación diferente, como defiende el giro ontológico, requiere de mediaciones capaces de regular las diferentes capacidades de acción reconocidas en los objetos, antes que una nueva formulación especulativa sobre el estatus ontológico del mundo -este es el programa en el que se ha embarcado una parte de la filosofía y de las ciencias sociales más atentas a los réditos de inmediatez académica que a los procelosos caminos de la investigación-. Precisamente, este trabajo nos anima a tomarnos en serio a las cosas a partir de un método que permita echar luz sobre un aspecto fundamental del proceso histórico, como es el peso de la materialidad en las pautas de acción y en la cognición humanas. Es también un modo de volver a pensar la 
vieja tesis de que la tecnología es un factor importante en el pensamiento humano, una idea sin la cual no se pueden entender los procesos de innovación ni de cambio tecnológico de cualquier fase histórica.

En quinto lugar, esta investigación muestra que la memoria desempeña una función básica en el proceso perceptual, y de paso amplía nuestra comprensión de este concepto clave para las ciencias sociales, históricas y cognitivas. No está clara la 'relación entre memoria social, memoria individual y memoria como proceso neuronal'. La neurociencia estándar no se preocupa mucho por la memoria y tiende a considerar que todo lo que no sea memoria individual es falsa memoria. Pero en realidad toda memoria es falsa. En el momento que algo es rememorado, se produce una ventaja de plasticidad que introduce en el "recuerdo" otros efectos. Como decía Oliver Sacks (2013), memory is dialogic and arises not only from direct experience but from the intercourse of many minds. El estudio de los mecanismos de la percepción muestra que las representaciones que construimos con los sentidos del mundo dependen más de procesos cognitivos que de estímulos perceptuales directos. Lo que vemos (igual que lo que escuchamos, que lo que sentimos con todos nuestros sentidos) es el resultado de un procesado cognitivo en el que los estímulos sensoriales son completados con base en un modelo del mundo creado previamente. Esto quiere decir que en realidad lo percibido depende al menos tanto de la memoria como de la percepción. Los estudios de cognición visual que glosamos en este trabajo, muestran que esa memoria es construida a partir de los estímulos externos del mundo, i. e. la experiencia. Como este mundo no es un mundo natural, sino un mundo trabado por relaciones sociales, un espacio producido, un mundo material construido por los humanos, lo que los humanos hacen da lugar a esos modelos y a la memoria. Dicho así, se unifican la memoria 'cerebral', la individual y la construcción social de ambas. La memoria social sería por lo tanto afín, si no idéntica, a las otras dos. Parece, pues, que armonizar las 'tres memorias' es más fácil de lo que podíamos prever. Pero esto mismo explica por qué la memoria es tan incierta. En vez de ser una constante, la memoria es el resultado de la actualización que en cada momento realizamos, social e individualmente, de nuestra tradición y experiencia previa en relación con las circunstancias del mundo en el que hacemos uso de ella. El arqueólogo Laurent Olivier (2008) plantea conclusiones parecidas en sus reflexiones sobre la memoria material de los vestigios arqueológicos. En este caso, desde una posición completamente distinta, la memoria también es el resultado de las alteraciones físicas que afectan al objeto arqueológico, las cuales terminan conformando una acumulación de huellas del pasado cuyo estudio es una especie de activación de la memoria fijada en ellas. Nosotros hemos probado la literalidad de este fenómeno en los procesos de cognición visual de la materialidad.

En suma, este trabajo abre un camino de futuras investigaciones que tornan verosímil plantear que 'la forma social guía la conciencia y esta reconstruye la forma social'. Considerada a la vista de estas observaciones, la frase de Marx "la conciencia no determina la existencia sino que esta determina a aquella" adquiere nuevo sentido, o más bien recupera el sentido que Marx le dio y que otras lecturas confundieron (Brown 2014: $110-111)^{8}$. Así, el viejo problema de la perseverancia de los modelos de racionalidad y la resistencia al cambio en las culturas humanas premodernas, alcanzaría de este modo un horizonte de inteligibilidad alternativo. Un horizonte desde el que podemos entrever que tal vez dispongamos en los mecanismos de la cognición visual de una constante histórica que nos permita aproximarnos con viabilidad al estudio de la preprogramación biológica de los seres humanos y el modo cómo esta constituye la conciencia, sin incurrir en un reduccionismo naturalista porque esos procesos habrían incorporado siempre de forma activa a la formación socio-cultural. Si es así, esto explica también por qué la tradición social, los estilos culturales y la cultura misma tienen tantas inercias y tienden tanto a la permanencia y a la continuidad. El cambio ofrece resistencias que nacen de la necesidad de generar modelos de un mundo que todavía no existe.

La versión extendida de la segunda hipótesis de este trabajo fue, de hecho, el punto de partida de esta investigación. Partimos de una conjetura que habíamos desarrollado como consecuencia de una serie de investigaciones en arqueología del paisaje que nos permitieron postular modelos concretos de concepción del espacio detrás de las formas de paisaje $\mathrm{y}$, más en general, de las formas específicas de la materialidad en sociedades distintivas (e. g. Criado-Boado y Villoch 1998). Entonces observamos que esos modelos parecían corresponderse con formas específicas de mirar (Prieto-Martínez et al. 2003: figs. 22 y 23). La reiteración de esta estructura espacial en diferentes códigos

\footnotetext{
${ }^{8} \mathrm{O}$ como también dice esta autora en otro pasaje comentando la metáfora visual de Marx: "con la imagen de la cámara obscura, Marx explica la inversión de la realidad llevada a cabo por la conciencia a la vez que ofrece un remedio potencial a tal inversión, que de hecho puede corregirse por completo del mismo modo que el cerebro corrige la inversión de las imágenes en la retina. Según Marx, la lógica de la inversión de la realidad llevada a cabo por la ideología es tan absoluta, necesaria e inevitable como la inversión de lo que vemos realizada por la retina. En ambos casos, la realidad no aparece distorsionada de modo casual sino que es exactamente al revés. Lo que en principio aparece como una metáfora o una homología entre visión y conciencia se convierte en un todo en el momento en que queda manifiesta la contigüidad entre los dos procesos que Marx analiza. La ideología no es solo comparable al proceso visual, sino que es también una manera de ver" (Brown 2014: 116-117).
} 
y contextos materiales de una misma formación sociocultural llevó a uno de los autores (FCB) a definir ese modelo ideal como xscape, es decir, la forma constante debajo de diferentes tipos de paisaje, landscape, skyscape, soundscape, emotionalscape, mindscape, ... 'xscape' (Criado-Boado 2014). La postulación de este tipo de estructuras era un constructo puramente teórico, aunque seguía un método interpretativo riguroso (más influenciado por las metodologías estructuralistas que hermenéuticas). Deriva de una aplicación heterodoxa de un planteamiento del antropólogo José Luis García (1988) que consiste en aislar los modelos concretos de cada código material o empírico analizado, comparándolos entre sí para reconocer, a través de las regularidades entre ellos, el modelo concreto ideal y, así sucesivamente, alcanzar un modelo genérico ideal (o estructura) (Criado-Boado 2013: fig. 31). Esto permitió definir un modelo teórico-conjetural para un programa de investigación en arqueología del paisaje más allá del estudio del medio, los usos y el simbolismo (concretada en Criado-Boado 2013). Pero siempre quedaba pendiente la confirmación o aceptabilidad de la propuesta básica, que preconiza la compatibilidad estructural entre el concepto cultural del espacio, las formas del paisaje (incluidas la arquitectura, la cultura material y el espacio doméstico e individual), y las características de cada formación social; de ahí las suspicacias de algunos críticos. Por ello, íntimamente convencidos de que si este modelo funcionaba tenía que dejar algún tipo de huella en la cognición, cuando uno de los autores (FCB) empezó a discutir esta aproximación, otro de ellos (LMM) apuntó que esta hipótesis se podría confirmar a través de una metodología de eye-tracking. Tal fue el punto de inicio para validar empíricamente una vieja hipótesis.

Como se dijo al inicio, esa hipótesis ya estaba en el artículo "Megalitos, espacio, pensamiento" (CriadoBoado 1989). La actual investigación nos permite ver que la relación estructural entre materialidades, pensamiento y mundo se basa en que el procesado cognitivo de la experiencia sensorial (la visión ante todo, pero no solo, pues lo mismo pasará con los restantes sentidos) crea una relación entre el sistema social y el mundo. La cuestión no es que la forma influya el modo de mirar. La cuestión clave es que lo hace de un modo que es homologable a las características del sistema social en el que es producida. Dado que el modo de ver está relacionado con la mente, con la racionalidad, lo que esto muestra es que 'las formas sociales influyen activamente sobre las formas de la racionalidad a través de la percepción de las formas materiales que producen'. Realmente lo que tenemos aquí es un lazo o pliegue (un loop) en el que todos estos procesos (pensar, hacer, ver) se retroalimentan activamente sobre unas bases que, siendo indeterminadas y contingentes (porque no están determinadas por la biología), incluyen los estratos de la historia. Quizás, el hecho de que esto sea así confirme el error de haber sustanciado cada uno de los procesos como si fueran elementos distintos, en vez de basar su separación por una cuestión analítica que no disuelva la base de su relación. De este modo, este trabajo mantiene la apuesta por construir una arqueología que sea capaz de elucidar problemas de investigación de interés general a partir de viejas tesis arqueológicas pensadas desde problemas y métodos nuevos que no son frecuentados por la investigación arqueológica más canónica. La arqueología puede y debe acometer este camino para rendir mejor servicio al público al que nos debemos.

\section{AGRADECIMIENTOS}

Yolanda Porto (réplicas), Anxo Rodríguez-Paz (dibujos), Elena Cabrejas (organizadora de voluntarios), Elena del Barrio, 106 voluntarios reconocidos pero anonimizados, miembros del Incipit, Alfredo González-Ruibal, Pablo Alonso González (comentadores), Ranquel Sánchez Martín (ayuda práctica).

\section{MATERIAL ADICIONAL}

Material adicional está disponible en el repositorio institucional del CSIC: Blanco, M. J.; Alonso-Pablos, D.; Martínez, L. M.; Criado-Boado, F.; 2017: Raw data of Eye-Tracking Analysis of archaeological material. Experiment 14061 [Dataset]. DIGITAL.CSIC. https://doi.org/10.20350/digitalCSIC/8511

\section{BIBLIOGRAFÍA}

Alberti, B.; Fowles, S.; Holbraad, M.; Marshall, Y. y Witmore, C. 2011: "'Worlds Otherwise'. Archaeology, Anthropology and Ontological Difference”. Current Anthropology 52 (6): 896-912. https://doi.org/10.1086/662027

Bradley, R. 2012: Idea of order. Oxford University Press. Oxford.

Brassier, R. 2011: "The view from nowhere". Identities. Journal for Politics, Gender and Culture 8(2): 7-23. https://doi.org/10.51151/identities.v8i2.262

Brown, W. 2014: La política fuera de la historia. Enclave de Libros. Madrid.

Clark, A. 2011: Supersizing the mind: Embodiment, action and cognitive extension. Oxford University Press. Oxford.

Clark, A. y Chalmers, D. J. 1998: "The extended mind". Analysis 58 (1): 7-19. https://doi.org/10.1093/analys/58.1.7

Criado-Boado, F. 1989: "Megalitos, espacio, pensamiento". Trabajos de Prehistoria 46: 75-98. https://doi.org/10.3989/tp.1989.v46.i0.588

Criado-Boado, F. 2012: Arqueológicas. La razón perdida. Edicions Be1laterra. Barcelona.

Criado-Boado, F. 2014: "Archaeologies of space: an inquiry into modes of existence of Xscapes”. En K. Kristiansen, L. Smejda y J. Turek (eds.): Paradigm found: Archaeological Theory - present, past and future. Essays in Honour of Evžen Neustupný. Oxbow Books. Oxford: 61-83. 
Criado-Boado, F.; Alonso-Pablos, D.; Blanco, M. J.; Porto, Y.; Rodríguez-Paz, A.; Cabrejas, E.... y Martínez, L. M. 2019: "Coevolution of visual behaviour, the material world and social complexity, depicted by the eye-tracking of archaeological objects in humans". Scientific Reports 9 (1): 3985. https://doi.org/10.1038/s41598-019-39661-w

Criado-Boado, F. y Villoch, V. 1998: "La monumentalización del paisaje: percepción actual y sentido original en el megalitismo de la Sierra de Barbanza (Galicia)". Trabajos de Prehistoria 55 (1): 63-80. https://doi.org/10.3989/tp.1998.v55.i1.317

Dobres, M. A. y Robb, J. 2000: Agency in archaeology. Routledge. Londres.

Dunbar, R. I. 2009: "The social brain hypothesis and its implications for social evolution". Annals of human biology 36(5): 562-72. https://doi.org/10.1080/03014460902960289

Dunbar, R. I.; Gamble, C. y Gowlett, J. A. J. (eds.) 2010: Social Brain, Distributed Mind. Proceedings of the British Academy.

Espinosa-Espinosa, D. y González-García, A. C. 2017: “ a. d. VIIII Kalendas Octobres, dies natalis Augusti. Some considerations on the astronomical orientation of Roman Cologne and the imperial cult". Numen 64 (5-6): 545-567. https://doi.org/10.1163/15685276-12341479

Field, D. J. 1987: "Relations between the statistics of natural images and the response properties of cortical cells". Journal of the Optical Society of America 4: 2379-2394. https://doi.org/10.1364/josaa.4.002379

Foucault, M. 1966: Las palabras y las cosas: una arqueología de las ciencias humanas. Siglo XXI, Madrid.

Gabriel, M. 2015. Por qué el mundo no existe. Pasado\&Presente, Madrid.

Gabriel, M. 2016: Yo no soy mi cerebro: Filosofía de la mente para el siglo XXI. Pasado\&Presente. Madrid.

Gallagher, S. y Zahavi, D. 2013: La mente fenomenológica. Alianza Editorial. Madrid.

García, J. L. 1988: “El tiempo cotidiano en Vilanova D’Oscos”. En Enciclopedia Temática de Asturias 9, Silverio Cañada. Gijón: 13-30.

Gianotti, C.; Mañana-Borrazás, P.; Criado-Boado, F. y López-Romero, E. 2011: "Deconstructing neolithic monumental space: the Montenegro enclosure in Galicia (Northwest Iberia)". Cambridge Journal of Archaeology 21 (3): 391-406. https://doi.org/10.1017/s0959774311000436

Gibson, A. M. 2002: Prehistoric pottery in Britain \& Ireland. Tempus Publishing Ltd. Stroud, Gloucestershire, Reino Unido.

González-García, A. C.; Vilas-Estévez, B.; López-Romero, E. y Mañana-Borrazas, P. 2019: "Domesticating light and shadows in the Neolithic: the Dombate Passage Grave (A Coruña, Spain)". Cambridge Archaeological Journal 29 (2): 327-343. https://doi.org/10.1017/s0959774318000562

Guattari, F. 1990: Las tres ecologías. Pre-Textos, Valencia.

Haraway, D. 1995: Ciencia, cyborgs y mujeres: la reinvención de la naturaleza. Cátedra. Madrid.

He, S. y Davis, W. L. 2001: "Filling-in at the natural blind spot contributes to binocular rivalry". Vision Research 41(7): 835-840. https://doi.org/10.1016/s0042-6989(00)00315-1

Heidegger, M. 1994a [1951]: "Construir, habitar, pensar". En M. Heidegger: Conferencias y escritos. Ediciones del Serbal. Barcelona: 127-142

Heidegger, M. 1994b [1977]: "The question concerning technology". En D. Krell (ed.): Basic writings. Harper \& Row. Nueva York: 307-341.

Hernando, A. 2012: La fantasía de la individualidad. Sobre la construcción sociohistórica del sujeto moderno. Katz Editores. Buenos Aires.

Hinton, L.; Nichols, J. y Ohala, J. (eds.) 1994: Sound symbolism. Cambridge University Press. Cambridge.

Hodder, I. 2012: Entangled: An archaeology of the relationships between humans and things. Wiley-Blackwell. Malden MA.

Hutchins, E. 1995: Cognition in the wild. MIT Press. Cambridge MA.

Ingold, T. 2007: "Materials against materiality". Archaeological dialogues 14(01): 1-16. https://doi.org/10.1017/s1380203807002127

Jablonka, E y Lamb, M. J. 2005: Evolution in four dimensions: genetic, epigenetic, behavioral, and symbolic variation in the History of Life. MIT Press. Cambridge MA.

Köhler, W. 1929: Gestalt psychology. Liveright. Nueva York.

Lakoff, G. J. y Johnson, M. 1980: Metaphors we live by. University of Chicago Press. Chicago.

Lange-Berndt, P. (ed.) 2015: Materiality. MIT Press. Cambridge.

Latour, B. 2005: Reassembling the social: An introduction to actor-network-theory. Oxford University Press. Oxford.
Lemonnier, P. 2012: Mundane objects: Materiality and non-verbal communication. Left Coast Press. Walnut Creek.

Malabou, C. 2012: The new wounded: From neurosis to brain damage. Fordham University Press. Nueva York.

Malabou, C. 2016: Before tomorrow: Epigenesis and rationality. Polity Press. Londres.

Malabou, C. 2017: Métamorphoses de l'intelligence. Que faire de leur cerveau bleu? PUF. París.

Malabou, C. y Johnston A. 2013: Self and emotional life: Philosophy, psychoanalysis and neuroscience. Columbia University Press. Nueva York.

Malafouris, L. 2010: "The brain-artefact interface (BAI): a challenge for archaeology and cultural neuroscience". SCAN 5: 264-273. https://doi.org/10.1093/scan/nsp057

Malafouris, L. 2013. How things shape the mind. MIT Press. Cambridge MA.

Martínez, L. M.; Molano-Mazón, M.; Wang, X.; Sommer, F. T. y Hirsch, J. A. 2014: "Statistical wiring of thalamic receptive fields optimizes spatial sampling of the retinal image". Neuron 81: 943-956. https://doi.org/10.1016/j.neuron.2013.12.014

Merleau-Ponty, M. 1945: Phenomenology of Perception. Routledge. Londres.

Meteyard, L.; Rodriguez Cuadrado, S.; Bahrami, B. y Vigliocco G. 2012. "Coming of age: A review of embodiment and the neuroscience of semantics". Cortex 48: 788-804. https://doi.org/10.1016/j.cortex.2010.11.002

Metzinger, T. 2009: The ego tunnel: The science of the mind and the myth of the self. Basic Books. Nueva York.

Minkowski, E. 1936: Vers une cosmologie: fragments philosophiques. Aubier. París.

Moos, A.; Simmons, D.; Simner, J. y Smith, R. 2013: "Color and texture associations in voice-induced synesthesia". Frontiers in Psychology 4: 568. https://doi.org/10.3389/fpsyg.2013.00568

Niubur, E. 2007: "Saliency map". Scholarpedia 2(8): 2675. https://doi.org/10.4249/scholarpedia.2675

Olivier, L. 2008: Le sombre abîme du temps. Mémoire et archéologie. Editions Seuil. París.

Olsen, B. 2011: In defense of things: archaeology and the ontology of objects. Altamira Press. Walnut Creek.

Olsen, B.; Shanks, M.; Webmoor, T. y Witmore, C. 2012: Archaeology. The discipline of things. University of California Press, Berkeley, Londres, Los Ángeles.

Prieto-Martínez, P. 2009: "From Galicia to the Iberian Peninsula: Neolithic ceramics and traditions". En G. Dragos (ed.): Early farmers, late foragers and ceramic traditions. On the beginning of pottery in Europe. Cambridge Scholars Press. Cambridge: 116-149.

Prieto-Martínez, P. 2017: "La Edad de los Metales: hacia la consolidación de la complejidad social desde inicios del III milenio a mediados del II milenio BC". En P. López-García (ed): La prehistoria en la península ibérica. Editorial Istmo. Madrid: 539-648.

Prieto Martínez, M. P.; Cobas Fernández, M. I. y Criado-Boado, F. 2003: "Patterns of spatial regularity in late prehistoric material culture styles of the NW Iberian Peninsula". En A. Gibson (ed.): Prehistoric pottery: people, patterns and purpose. British Archaeological Reports International Series 1156, Archaeopress. Oxford: 147-187.

Renfrew, C. 2008: "Neuroscience, evolution and the sapient paradox: the factuality of value and of the sacred". Philosophical Transactions of the Royal Society 363: 2041-2047. https://doi.org/10.1098/rstb.2008.0010

Renfrew, C.; Frith, C. y Malafouris, L. 2008: The sapient mind. Archaeology meets neuroscience. Oxford University Press. Oxford.

Reynoso, C. 2015: Crítica de la antropología perspectivista: Viveiros de Castro, Philippe Descola, Bruno Latour. Sb Editorial. Buenos Aires.

Robinson, S. y Pallasmaa, J. 2015: Mind in architecture. Neuroscience, embodiment, and the future of design. The MIT Press, Cambridge, Massachusetts.

Ruderman, D. L. 1994: "The statistics of natural images". Network 5: 517-548. https://doi.org/10.1088/0954-898x_5_4_006

Sacks, O. 2013: "Speak, Memory". The New York Review of Books, February 212013. 
Santos Estévez, M. 2012: "Atlantic rock art: transformation and tradition during Late Prehistory”. En M. Cruz Berrocal, L. García Sanjuán y A. Gilman (eds.): The Prehistory of Iberia. Debating early social stratification and the state. Routledge. Oxford: 231-248.

Sigman, M.; Cecchi, G. A.; Gilbert, C. D. y Magnasco, M. O. 2001: "On a common circle: natural scenes and Gestalt rules". Proceedings of the National Academy of Sciences 98(4): 1935-1940. https://doi.org/10.1073/pnas.98.4.1935

Smail, D. 2008: On deep history and the brain. University of California Press. Berkeley.

Sohn-Rethel, A. 2017: Trabajo manual y trabajo intelectual: una crítica de la epistemología. Dado Editores. Madrid.

Solms, M. y Turnbull, O. 2002: The brain and the inner world: An introduction to the neuroscience. Karnac. Londres.

Stiegler, B. 2002: La técnica y el tiempo: el pecado de Epimeteo. Cultura Libre. Hondarribia.

Torralba, A. y Oliva, A. 2003: "Statistics of natural image categories". Network: Computing in Neural Systems 14: 391-412. https://doi.org/10.1088/0954-898x_14_3_302
Troncoso, A. 2019: "Rock art, historical ontologies and the genealogy of landscape: a case study from the Southern Andes". En M. C. Lozada y H. Tantaleán (eds.): Andean ontologies: New perspectives from archaeology, bioarchaeology and linguistics. University Press of Florida. Gainesville: 301-331.

Troncoso A.; Criado-Boado F. y Santos-Estévez M. 2011: “Arte rupestre y códigos espaciales: un caso de estudio en Chile Central”. Chungara, Revista de Antropología Chilena 43 (2): 161-176.

Troncoso, A.; Salazar, D.; Parcero-Oubiña, C.; Hayashida, F.; FábregaÁlvarez, P. y Larach, P. 2019: "Maquetas incaicas en Chiuchiu: paisaje y ritualidad agraria en el desierto de Atacama". Estudios Atacameños 63: 3-23.

Tsur, R. 2006: "Size-sound symbolism revisited". Journal of Pragmatics 38: 905-924. https://doi.org/10.1016/j.pragma.2005.12.002

Wilson, A. D. y Golonka, S. 2013: "Embodied cognition is not what you think it is". Frontiers in Psychology 4(58): 1-13. https://doi.org/10.3389/fpsyg.2013.00058

Witmore, C. 2014: "Archaeology and the New Materialism". Journal of Contemporary Archaeology 1(2): 203-246. https://doi.org/10.1558/jca.v1i2.16661 